\title{
Article \\ Stability and Manoeuvrability Simulation of a Semi-Autonomous Submarine Free-Running Model SUBOFF with an Autopilot System
}

\author{
Yu-Hsien Lin *, Yu-Ting Lin and Yen-Jun Chiu
}

check for updates

Citation: Lin, Y.-H.; Lin, Y.-T.; Chiu, Y.-J. Stability and Manoeuvrability Simulation of a Semi-Autonomous Submarine Free-Running Model SUBOFF with an Autopilot System. Appl. Sci. 2021, 11, 410. https:// doi.org/10.3390/app11010410

Received: 16 November 2020 Accepted: 30 December 2020 Published: 4 January 2021

Publisher's Note: MDPI stays neutral with regard to jurisdictional clai$\mathrm{ms}$ in published maps and institutional affiliations.

Copyright: $(2021$ by the authors. Licensee MDPI, Basel, Switzerland. This article is an open access article distributed under the terms and conditions of the Creative Commons Attribution (CC BY) license (https:// creativecommons.org/licenses/by/ $4.0 /)$.
Department of Systems \& Naval Mechatronic Engineering, National Cheng-Kung University, Tainan City 70101, Taiwan; timmy850202@yahoo.com.tw (Y.-T.L.); p16081033@ncku.edu.tw (Y.-J.C.)

* Correspondence: vyhlin@mail.ncku.edu.tw

\begin{abstract}
On the basis of a full-appendage DARPA SUBOFF model (DTRC model 5470$)$, a scale $(\lambda=0.535)$ semi-autonomous submarine free-running model (SFRM) was designed for testing its manoeuvrability and stability in the constrained water. Prior to the experimental tests of the SFRM, a six-degree-offreedom (6-DOF) manoeuvre model with an autopilot system was developed by using logic operations in MATLAB. The SFRM's attitude and its trim polygon were presented by coping with the changes in mass and trimming moment. By adopting a series of manoeuvring tests in empty tanks, the performances of the SFRM were introduced in cases of three sailing speeds. In addition, the PD controller was established by considering the simulation results of these manoeuvring tests. The optimal control gains with respect to each manoeuvring test can be calculated by using the PID tuner in MATLAB. Two sets of control gains derived from the optimal characteristics parameters were compared in order to decide on the most appropriate PD controller with the line-of-sight (LOS) guidance algorithm for the SFRM in the autopilot simulation. Eventually, the simulated trajectories and course angles of the SFRM would be illustrated in the post-processor based on the Cinema 4D modelling.
\end{abstract}

Keywords: submarine free-running model; trim polygon; manoeuvrability; SUBOFF; PD controller; autopilot system

\section{Introduction}

The manoeuvring performance of the submarine is an important parameter in the initial design, especially for the geometry of the appendages, which in turn is important for the submarine resistance and hence total performance of the submarine. Conventionally, captive experiments, i.e., rotating arm (RA) and planar motion mechanism (PMM), and numerical simulations, i.e., computerised planar motion mechanism (CPMM), are adopted for in the early design stage until a reasonable maturity of the design is reached. For an alternative option of matured designs, free-running manoeuvring models have further become available for validation of the manoeuvring performance.

The so-called submarine free-running model (SFRM) is a remotely controlled scale model replicating submarine manoeuvres. These models should be equipped with instrumentation to measure all the state variables required to describe its 6-DOF motion responses, including trajectories, attitudes, linear and angular velocities, and accelerations [1]. Over the last few decades, there have been numerous studies [2-5] investigating SFRMs in controlled environments. Although the SFRM can evaluate the manoeuvring performances of the full-scale model accurately, there are still some differences between the scale model and the full-scale model due to scale effect.

In order to keep the desired trajectories dynamically during the test, a robust control system is required for adjusting the control planes of the SFRM. Definitely, the input and output signals demand for the control planes are greatly affected by the manoeuvring characteristics. The CFD-based and coefficient-based methods are the two major mathematical 
models in exploring the hydrodynamic forces and moments exerted on the SFRM. As the name implies, the coefficient-based method uses the equation of motion (EOM) combined with the hydrodynamic coefficient as a mathematical model [6,7]. Taking advantage of the predefined coefficients in the mathematical model, it usually has less computation time than the CFD-based method. Furthermore, the coefficient-based method can approximate the hydrodynamic interaction effect through semi-empirical correction when the positions of the appendages are rearranged at a preliminary design stage [8]. However, the limitation of the coefficient-based method is that the unsteady viscous effect cannot be captured in the linear model, such as cross flow and vorticity [1]. In order to overcome the limitations of the coefficient-based method and improve the accuracy of manoeuvring characteristics, the CFD-based method provides another option, including the resistance test [9], self-propulsion test, and free-running test simulations [10].

Since the estimation of hydrodynamic coefficients has uncertainty and variation in different environmental conditions [11], hydrodynamic forces and moments exerted on the SFRM are changed accordingly. Therefore, an applicable controller needs to be a self-tuning and robust counter to the variation of SFRM parameters and also unpredictable environmental disturbances. In recent years, numerous control models have been proposed, e.g., linear controllers [12,13], sliding-mode controller (SMC) [14], adaptive control [15,16], FLC (Fuzzy Logic Control) [17], predictive control [18], static feedback control [19], neural-network-based control [20], and PID (proportional-integral-derivative) control [21]. The advantage of using a PID controller is that it is simple to implement and maintain, but it is primarily applicable for linear time-invariant systems.

The well-known classic equations of motion (EOMs) are those of Gertler and Hagen [6], Feldman [7], and Fossen and Fjellstad [22]. They were derived by adopting Newton-Euler equations or Lagrangian methods, which can be calculated in matrix forms. For example, Perrault, et al. [23] applied a fully nonlinear mathematical model based on Newton-Euler EOMs to investigate the sensitivity of an AUV response to changes in hydrodynamic coefficients, including those during simulated turning and zigzag tests. Coe [24] established a preliminary model for manoeuvrability computation of a submarine by using a database of hydrodynamic coefficients and empirical equations, thus enabling the prediction of submarine's general manoeuvrability in deep water. Although it is difficult to realise unsteady motions for extreme submarine manoeuvres [25], the coefficient-based model is considered to provide realistic estimations for moderate manoeuvres [1].

The main purpose of this study is to develop a 6-DOF manoeuvre model of the SFRM based on the generic model SUBOFF by means of a conventional PD controller. First of all, a six-degree-of-freedom (6-DOF) manoeuvre model was constructed for a series of fundamental manoeuvring tests. Secondly, the integrated control system, including rudder planes and stern planes, were modelled as 2nd order mass-spring systems that can be simulated as control inputs. Finally, the PD controller combined with the line-of-sight (LOS) [26] guidance algorithm was applied to track waypoints at different sailing speeds.

\section{The Configuration of SFRM}

\subsection{Geometry}

Our SFRM was developed based on the scale $(\lambda=0.535)$ DARPA SUBOFF (DTRC model 5470) [27]. The principal model architecture comprises of the bow, midsection, stern, sail, rudder, and stern planes. The model geometry and principal particulars were presented in Figure 1 and Table 1, respectively. In Table 1, the effective power is equal to the power output of the engine minus losses due to the gearbox, shafting, propeller, as well as interaction between the propeller and the hull. 


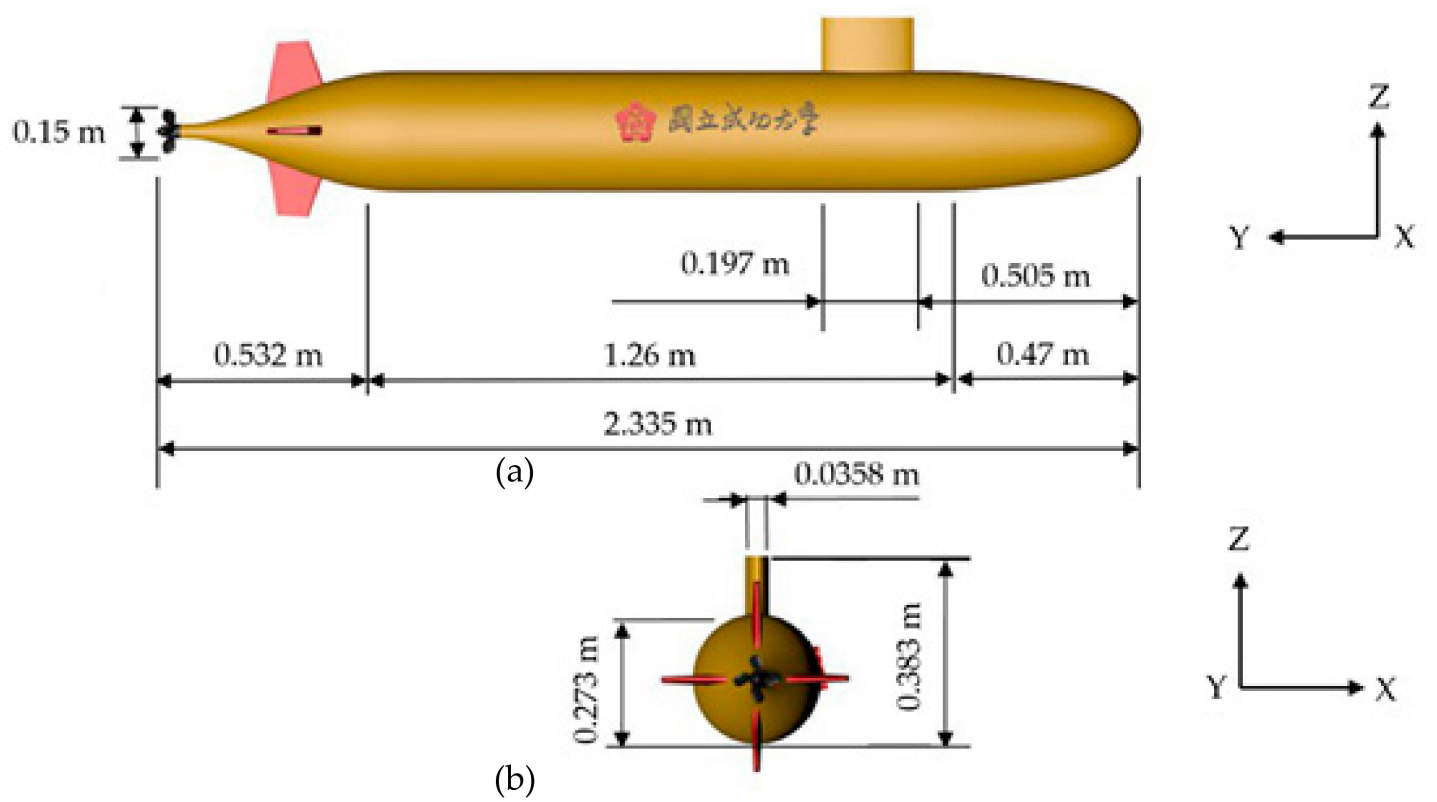

Figure 1. (a) Side, and (b) rear view of the submarine free-running model (SFRM).

Table 1. Principal particulars of the SFRM and the propeller.

\begin{tabular}{cc}
\hline & SFRM \\
\hline Full length $[\mathrm{m}]$ & 2.335 \\
\hline Diameter $[\mathrm{m}]$ & 0.273 \\
\hline Bow length [m] & 0.47 \\
\hline Midsection length [m] & 1.26 \\
\hline Stern length [m] & 0.532 \\
\hline Total height $[\mathrm{m}]$ & 0.383 \\
\hline Sail length $[\mathrm{m}]$ & 0.197 \\
\hline Sail width $[\mathrm{m}]$ & 0.0358 \\
\hline & \\
\hline Diameter $[\mathrm{m}]$ & 0.15 \\
\hline Number of blades & 4 \\
\hline Hub to diameter ratio & 0.292 \\
\hline Pitch to diameter ratio & 1.32 \\
\hline Revolution speed $[R P M]$ & 370 at $U=0.5[\mathrm{~m} / \mathrm{s}]$ \\
& 785 at $U=1.0[\mathrm{~m} / \mathrm{s}]$ \\
\hline Effective Power $[W]$ & 1210 at $U=1.5[\mathrm{~m} / \mathrm{s}]$ \\
\hline & 0.17 at $U=0.5[\mathrm{~m} / \mathrm{s}]$ \\
1.51 at $U=1.0[\mathrm{~m} / \mathrm{s}]$ \\
4.44 at $U=1.5[\mathrm{~m} / \mathrm{s}]$ \\
\hline
\end{tabular}

\subsection{Ballast Tank and Attitude Adjusting System}

Our SFRM contains forward, aft ballast tanks, and an attitude adjusting system that allows the variation of mass, and movement of mass inside the model as shown in Figure 2. The designs of ballast tanks were maximised within the constraints of the hull geometry. The forward and aft ballast tanks are of the same design, approximately equal distance from midships, but each one can be independently controlled. The dimension of each ballast tank is $0.084 \mathrm{~m} \times 0.084 \mathrm{~m} \times 0.084 \mathrm{~m}$, and the weight of the full tank is $600 \mathrm{~g}$. In addition, both the inflow rate and the outflow rate are set to be $0.0002 \mathrm{~m}^{3} / \mathrm{s}$. For the 
attitude adjusting system, the trim angle and the heel angle of the SFRM can be controlled suitably by fine-tuning the locations of the lead weights. Overall speaking, the total mass, center of gravity (CG), trim angle and heel angle can be regulated suitably by using ballast tanks and the attitude adjusting system.

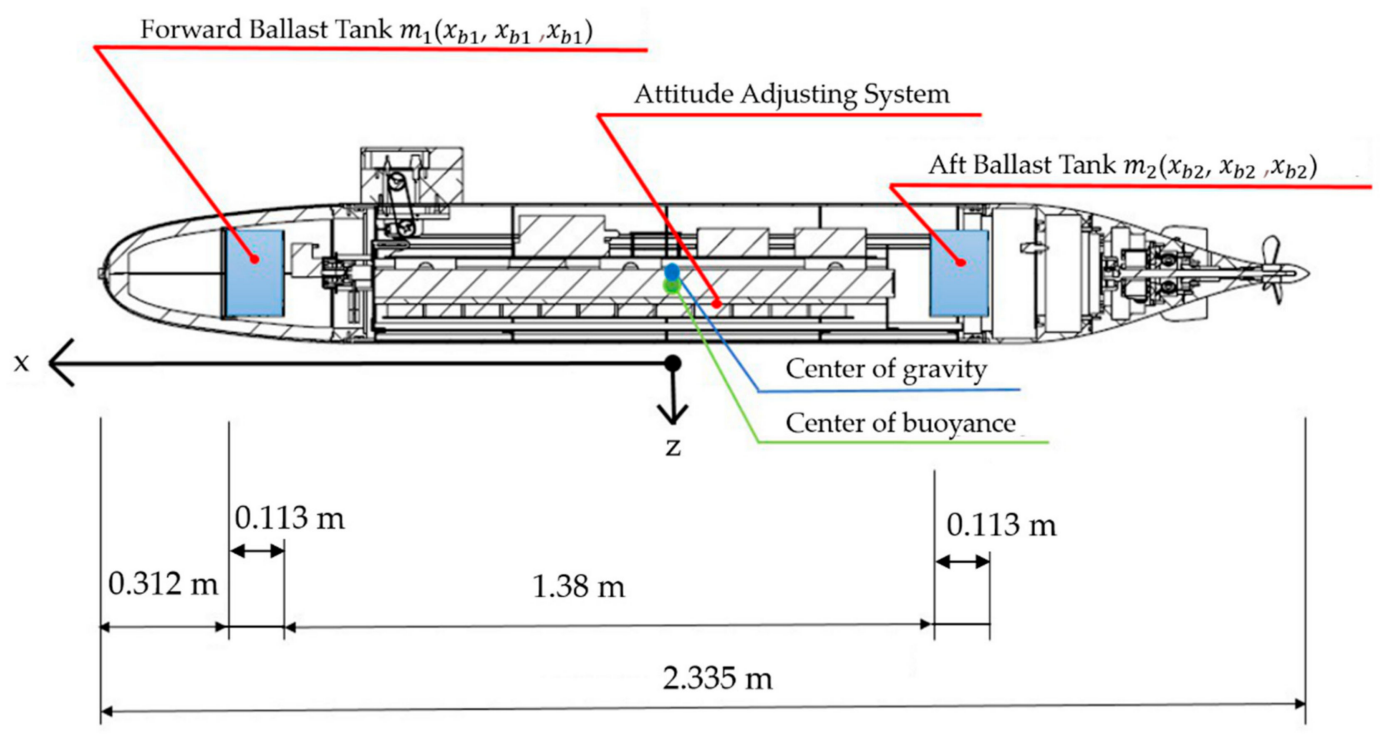

Figure 2. The configuration of ballast tanks and the attitude adjusting system.

\subsection{Time-Varying Mass Model}

The total mass and weight of the SFRM can be time-varied based on the following equations:

$$
\begin{gathered}
W(t)=m(t) g \\
m(t)=m_{0}+\sum_{i=1}^{2} m_{i}(t) \\
m_{i}(t)=\int \dot{m}_{i}(t) d t=\rho Q_{i}(t), i=1,2
\end{gathered}
$$

where $t$ is defined as time; $W(t)$ and $m(t)$ are the total weight and mass of the SFRM; $m_{0}$ is the initial mass of the SFRM; $m_{1}(t)$ and $m_{2}(t)$ represent the masses of forward ballast tank and aft ballast tank; $\dot{m}_{1}(t)$ and $\dot{m}_{2}(t)$ denote the rates of masses of forward ballast tank and aft ballast tank; $Q_{1}(t)$ and $Q_{2}(t)$ denote the flow rates of forward ballast tank and aft ballast tank; $\rho$ is the water density; $t$ is defined as time.

Since the attitude of the SFRM is determined by the mass variation of the ballast tank, the coordinate of CG can be determined as below:

$$
\begin{aligned}
& x_{g}(t)=\frac{m_{0} x_{g_{o}}+x_{b 1}(t) m_{1}(t)+x_{b 2}(t) m_{2}(t)}{m_{0}+m_{1}(t)+m_{2}(t)} \\
& y_{g}(t)=\frac{m_{0} y_{g o}+y_{b 1}(t) m_{1}(t)+y_{b 2}(t) m_{2}(t)}{m_{0}+m_{1}(t)+m_{2}(t)} \\
& z_{g}(t)=\frac{m_{0} z_{z_{o}}+z_{b 1}(t) m_{1}(t)+z_{b 2}(t) m_{2}(t)}{m_{0}+m_{1}(t)+m_{2}(t)}
\end{aligned}
$$

where $\left(x_{g o}, y_{g o}, z_{g o}\right)$ is the initial coordinate of CG; $\left(x_{b 1}, y_{b 1}, z_{b 1}\right)$ is the coordinate of CG for the forward ballast tank, and $\left(x_{b 2}, y_{b 2}, z_{b 2}\right)$ is the coordinate of CG for the aft ballast tank.

Subsequently, the inertia moments of the SFRM are defined by: 


$$
\begin{gathered}
I_{x x}(t)=I_{x 0}+\left[I_{x b 1}(t)+\left(y_{b 1}(t)^{2}+z_{b 1}(t)^{2}\right) \times m_{1}(t)\right]+\left[I_{x b 2}(t)+\left(y_{b 2}(t)^{2}+z_{b 2}(t)^{2}\right) \times m_{2}(t)\right] \\
I_{y y}(t)=I_{y 0}+\left[I_{y b 1}(t)+\left(x_{b 1}(t)^{2}+z_{b 1}(t)^{2}\right) \times m_{1}(t)\right]+\left[I_{y b 2}(t)+\left(x_{b 2}(t)^{2}+z_{b 2}(t)^{2}\right) \times m_{2}(t)\right] \\
I_{z z}(t)=I_{z 0}+\left[I_{z b 1}(t)+\left(x_{b 1}(t)^{2}+y_{b 1}(t)^{2}\right) \times m_{1}(t)\right]+\left[I_{z b 2}(t)+\left(x_{b 2}(t)^{2}+y_{b 2}(t)^{2}\right) \times m_{2}(t)\right] \\
I_{x y}(t)=I_{x y 0}+\left[I_{x y b 1}(t)+x_{b 1}(t) y_{b 1}(t) m_{1}(t)\right]+\left[I_{x y b 2}(t)+x_{b 2}(t) y_{b 2}(t) m_{2}(t)\right] \\
I_{x z}(t)=I_{x z 0}+\left[I_{x z b 1}(t)+x_{b 1}(t) z_{b 1}(t) m_{1}(t)\right]+\left[I_{x z b 2}(t)+x_{b 2}(t) z_{b 2}(t) m_{2}(t)\right] \\
I_{y z}(t)=I_{y z 0}+\left[I_{y z b 1}(t)+y_{b 1}(t) z_{b 1}(t) m_{1}(t)\right]+\left[I_{y z b 2}(t)+y_{b 2}(t) z_{b 2}(t) m_{2}(t)\right]
\end{gathered}
$$

where $I_{x 0}, I_{y 0}, I_{z 0}, I_{x y 0}, I_{x z 0}$, and $I_{y z 0}$ are the inertia moments of the SFRM corresponding to the origin of the initial coordinate; $I_{x b 1}, I_{y b 1}, I_{z b 1}, I_{x y b 1}, I_{x z b 1}$, and $I_{y z b 1}$ are the inertia moments due to mass variation corresponding to the CG of the forward ballast tank; $I_{x b 2}$, $I_{y b 2}, I_{z b 2}, I_{x y b 2}, I_{x z b 2}$, and $I_{y z b 2}$ are the inertia moments due to mass variation corresponding to the CG of the aft ballast tank.

In conditions of full ballast tanks, the weight of either the forward or aft water tank is about $600 \mathrm{~g}$. Since the mass variation of ballast tanks causes the change of the pitch angle, the time-varying mass model would be adopted to understand the time series of the SFRM's attitude in the powerless state. Due to asymmetrical positions of ballast tanks on both sides of the SFRM, the time-varying model of each individual ballast tank was used to discuss the effect of ballast tanks on the inertia moments in this study.

\section{Mathematical Model}

\subsection{Coordinate Systems}

The earth-fixed coordinate system O-XYZ as shown in Figure 3a and the body-fixed coordinate system o-xyz as shown in Figure $3 b-d$ were considered in this study. The velocity component of the body-fixed coordinate system was $(u, v, w, p, q, r)$, and the position in body-fixed coordinate system was $(X, Y, Z)$. The three Euler angles of the body-fixed coordinate system relative to the earth-fixed coordinate system were expressed as $\phi$ (roll), $\theta$ (pitch), and $\psi$ (yaw). The parameters of the six degree-of-freedom (6-DOF) motion are presented in Table 2.

Table 2. Parameters of the six-degree-of-freedom (6-DOF) motion.

\begin{tabular}{ccc}
\hline Degree of Freedom & Velocity/Angular Velocity & Position/Angle \\
\hline Surge & $u$ & $X$ \\
\hline Sway & $v$ & $Y$ \\
\hline Heave & $w$ & $Z$ \\
\hline Roll & $p$ & $\phi$ \\
\hline Pitch & $q$ & $\theta$ \\
\hline Yaw & $r$ & $\psi$ \\
\hline
\end{tabular}




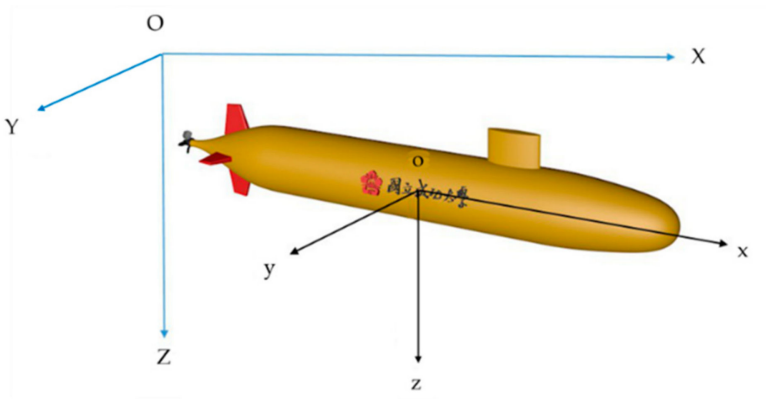

(a)

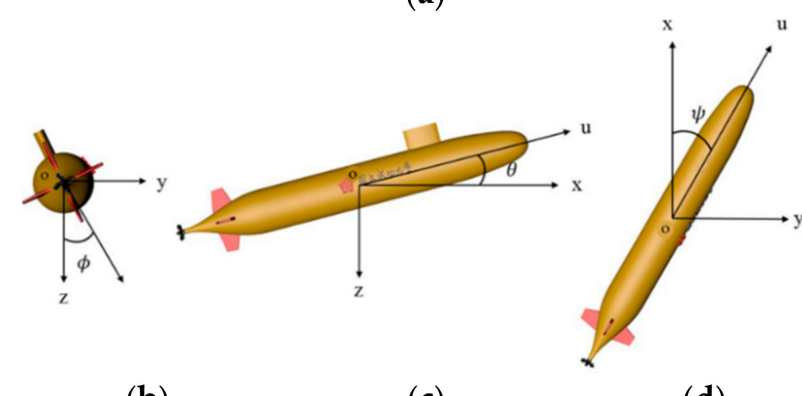

(b)

(c)

(d)

Figure 3. (a) The earth-fixed coordinate system; (b) rear, (c) side, and (d) top views of the body-fixed coordinate system.

In order to define the relationship between the body-fixed linear and angular velocities and the time derivative of the earth-fixed vehicle position coordinates, the transformation [28] can be related by

$$
\begin{aligned}
{\left[\begin{array}{l}
\dot{X} \\
\dot{Y} \\
\dot{Z}
\end{array}\right]=\left[\begin{array}{ccc}
\cos \psi \cos \theta & \cos \psi \sin \phi \sin \theta & \sin \phi \sin \psi+ \\
& -\sin \psi \cos \phi & \cos \psi \cos \phi \sin \theta \\
\sin \psi \cos \theta & \sin \psi \sin \phi \sin \theta & \sin \psi \cos \phi \sin \theta \\
+\cos \psi \cos \phi & -\cos \psi \sin \phi \\
-\sin \theta & \sin \phi \cos \theta & \cos \phi \cos \theta
\end{array}\right]\left[\begin{array}{c}
u \\
v \\
w
\end{array}\right] } \\
{\left[\begin{array}{c}
\dot{\phi} \\
\dot{\theta} \\
\dot{\psi}
\end{array}\right]=\left[\begin{array}{ccc}
1 & \sin \phi \tan \theta & \cos \phi \tan \theta \\
0 & \cos \phi & -\sin \phi \\
0 & \sin \phi / \cos \theta & \cos \phi / \cos \theta
\end{array}\right]\left[\begin{array}{l}
p \\
q \\
r
\end{array}\right] . }
\end{aligned}
$$

\subsection{Six-Degree-of-Freedom Motion Equations}

According to Newton's Second Law, the equations of motion [7] to represent hydrodynamic forces and moments as functions of motion variables were introduced in Equations (15)-(20). The left-hand side of the equations is the rigid body dynamics, whereas the right-hand side represents the hydrodynamic force acting on the SFRM.

1 Surge

$$
\begin{aligned}
& m\left[\dot{u}-v r+w q-x_{G}\left(q^{2}+r^{2}\right)+y_{G}(p q-\dot{r})+z_{G}(p r+\dot{q})\right] \\
& =\frac{\rho}{2} L^{4}\left[X_{q q}^{\prime} q^{2}+X_{r r}^{\prime} r^{2}+X_{r p}^{\prime} r p\right]+\frac{\rho}{2} L^{3}\left[X_{\dot{u}}^{\prime} \dot{u}+X_{v r}^{\prime} v r+X_{w q}^{\prime} w q\right] \\
& +\frac{\rho}{2} L^{2}\left[X_{u u}^{\prime} u^{2}+X_{v v}^{\prime} v^{2}+X_{w w}^{\prime} w^{2}\right]+\frac{\rho}{2} L^{2} u^{2}\left[X_{\delta_{r} \delta_{r}}^{\prime} \delta_{r}{ }^{2}+X_{\delta_{s} \delta_{s}}^{\prime} \delta_{s}{ }^{2}+X_{\delta_{b} \delta_{b}}^{\prime} \delta_{b}{ }^{2}\right] \\
& -(W-B) \sin \theta+X_{P}-X_{R}
\end{aligned}
$$


2 Sway

$$
\begin{aligned}
& m\left[\dot{v}+u r-w p+x_{G}(p q+\dot{r})-y_{G}\left(p^{2}+r^{2}\right)+z_{G}(q r-\dot{p})\right] \\
& =\frac{\rho}{2} L^{4}\left[Y_{\dot{p}}^{\prime} \dot{p}+Y_{\dot{r}}^{\prime} \dot{r}+Y_{p q}^{\prime} p q+Y_{p|p|}^{\prime} p|p|\right] \\
& +\frac{\rho}{2} L^{3}\left[Y_{\dot{v}}^{\prime} \dot{v}+Y_{w p}^{\prime} w p+Y_{v|r|}^{\prime} \frac{v}{|v|}\left|\left(v^{2}+w^{2}\right)^{\frac{1}{2}}\right||r|+Y_{p} u p+Y_{r} u r\right] \\
& +\frac{\rho}{2} L^{2}\left[Y_{u u}^{\prime} u^{2}+Y_{v} u v+Y_{v|v|}^{\prime} v\left|\left(v^{2}+w^{2}\right)^{\frac{1}{2}}\right|+Y_{w v} w v\right]+\frac{\rho}{2} L^{2} u^{2} Y_{\delta_{r}}^{\prime} \delta_{r} \\
& +(W-B) \cos \theta \sin \phi+\frac{\rho}{2} L^{2}\left(F_{y}\right)_{v s} \frac{v^{2}+w^{2}}{u^{2}}(-w) \sin \omega t+W F_{s}
\end{aligned}
$$

3 Heave

$$
\begin{aligned}
& m\left[\dot{w}-u q+v p+x_{G}(p r-\dot{q})+y_{G}(q r+\dot{p})-z_{G}\left(p^{2}+q^{2}\right)\right] \\
& =\frac{\rho}{2} L^{4}\left[Z_{\dot{q}}^{\prime} \dot{q}+Z_{r r}^{\prime} r^{2}+Z_{r p}^{\prime} r p\right]+\frac{\rho}{2} L^{3}\left[Z_{\dot{w}}^{\prime} \dot{w}+Z_{v r}^{\prime} v r+Z_{v p}^{\prime} v p\right] \\
& +\frac{\rho}{2} L^{3}\left[Z_{q}^{\prime} u q+Z_{w|q|}^{\prime} \frac{w}{|w|}\left|\left(v^{2}+w^{2}\right)^{\frac{1}{2}}\right||q|\right] \\
& +\frac{\rho}{2} L^{2}\left[Z_{u u}^{\prime} u^{2}+Z_{w}^{\prime} u w+Z_{w|w|}^{\prime} w\left|\left(v^{2}+w^{2}\right)^{\frac{1}{2}}\right|\right] \\
& +\frac{\rho}{2} L^{2}\left[Z_{|w|}^{\prime} u|w|+Z_{w w}^{\prime}\left|w\left(v^{2}+w^{2}\right)^{\frac{1}{2}}\right|+Z_{v v}^{\prime} v^{2}\right]+\frac{\rho}{2} L^{2} u^{2}\left[Z_{\delta_{s}}^{\prime} \delta_{s}+Z_{\delta_{b}}^{\prime} \delta_{b}\right] \\
& +(W-B) \cos \theta \cos \phi+\frac{\rho}{2} L^{2}\left(F_{z}\right)_{v s} \frac{v^{2}+w^{2}}{u^{2}} v \sin \omega t+W F_{H}
\end{aligned}
$$

4 Roll

$$
\begin{aligned}
& I_{x} \dot{p}+\left(I_{z}-I_{y}\right) q r-(\dot{r}+p q) I_{x z}+m\left[y_{G}(\dot{w}-u q+v p)-z_{G}(\dot{v}+u r-w p)\right] \\
& =\frac{\rho}{2} L^{5}\left[K_{\dot{p}}^{\prime} \dot{p}+K_{\dot{r}}^{\prime} \dot{r}+K_{q r}^{\prime} q r+K_{p|p|}^{\prime} p|p|\right] \\
& +\frac{\rho}{2} L^{4}\left[K_{p}^{\prime} u p+K_{r}^{\prime} u r+K_{\dot{v}}^{\prime} \dot{v}+K_{w p}^{\prime} w p\right] \\
& +\frac{\rho}{2} L^{3}\left[K_{u u}^{\prime} u^{2}+K_{v}^{\prime} u v+K_{v w}^{\prime} v w+K_{v|v|}^{\prime} v\left|\left(v^{2}+w^{2}\right)^{\frac{1}{2}}\right|\right]+\frac{\rho}{2} L^{3} u^{2} K_{\delta_{r}}^{\prime} \delta_{r} \\
& +\left(W y_{G}-B y_{B}\right) \cos \theta \cos \phi-\left(W z_{G}-B z_{B}\right) \cos \theta \sin \phi+W F_{R}
\end{aligned}
$$

\section{Pitch}

$$
\begin{aligned}
& I_{y} \dot{q}+\left(I_{x}-I_{z}\right) p r+\left(p^{2}-r^{2}\right) I_{x z}-m\left[x_{G}(\dot{w}-u q+v p)-z_{G}(\dot{u}-v r+w q)\right] \\
& =\frac{\rho}{2} L^{5}\left[M_{\dot{q}}^{\prime} \dot{q}+M_{r r}^{\prime} r^{2}+M_{r p}^{\prime} r p\right] \\
& +\frac{\rho}{2} L^{4}\left[M_{q}^{\prime} u q+M_{|w| q}^{\prime}\left|\left(v^{2}+w^{2}\right)^{\frac{1}{2}}\right| q+M_{\dot{w}}^{\prime} \dot{w}+M_{v r}^{\prime} v r+M_{v p}^{\prime} v p\right] \\
& +\frac{\rho}{2} L^{3}\left[M_{u u}^{\prime} u^{2}+M_{w}^{\prime} u w+M_{w|w|}^{\prime} w\left|\left(v^{2}+w^{2}\right)^{\frac{1}{2}}\right|\right] \\
& +\frac{\rho}{2} L^{3}\left[M_{|w|}^{\prime} u|w|+M_{w w}^{\prime}\left|w\left(v^{2}+w^{2}\right)^{\frac{1}{2}}\right|+M_{v v}^{\prime} v^{2}\right]+\frac{\rho}{2} L^{3} u^{2}\left[M_{\delta_{s}}^{\prime} \delta_{s}+M_{\delta_{b}}^{\prime} \delta_{b}\right] \\
& -\left(W x_{G}-B x_{B}\right) \cos \theta \cos \phi-\left(W z_{G}-B z_{B}\right) \sin \theta+W F_{P}
\end{aligned}
$$

6 Yaw

$$
\begin{aligned}
& I_{z} \dot{r}+\left(I_{y}-I_{x}\right) p q+(r q-\dot{p}) I_{x z}+m\left[x_{G}(\dot{v}+u r-w p)-y_{G}(\dot{u}-v r+w q)\right] \\
& =\frac{\rho}{2} L^{5}\left[N_{\dot{r}}^{\prime} \dot{r}+N_{p q}^{\prime} p q+N_{\dot{p}}^{\prime} \dot{p}\right] \\
& +\frac{\rho}{2} L^{4}\left[N_{r}^{\prime} u r+N_{|v| r}^{\prime}\left|\left(v^{2}+w^{2}\right)^{\frac{1}{2}}\right| r+N_{p}^{\prime} u p+N_{\dot{v}}^{\prime} \dot{v}+N_{w p}^{\prime} w p\right] \\
& +\frac{\rho}{2} L^{3}\left[N_{u u}^{\prime} u^{2}+N_{v}^{\prime} u v+N_{v|r|}^{\prime}\left|\left(v^{2}+w^{2}\right)^{\frac{1}{2}}\right|+N_{w v}^{\prime} w v\right]+\frac{\rho}{2} L^{3} u^{2} N_{\delta_{r}}^{\prime} \delta_{r} \\
& +\left(W x_{G}-B x_{B}\right) \cos \theta \cos \phi+\left(W y_{G}-B y_{B}\right) \sin \theta+W F_{Y}
\end{aligned}
$$

where $I_{x}, I_{y}$, and $I_{z}$ are the inertia moments about the axes of the body-fixed coordinate system, and $I_{x z}$ is the cross-sectional area on plane $x z . X_{P}$ and $X_{R}$ are defined as the 
propeller thrust and the resistance, respectively. $W F_{S}, W F_{H}, W F_{R}, W F_{P}$, and $W F_{Y}$ are the exciting forces of waves that act on each DOF motion. Since the manoeuvre of the SFRM was given in the condition of neutral buoyancy, the effects of wave exciting forces have been disregarded.

\subsection{Parameter Settings for Hydrodynamic Coefficients}

The SFRM was designed and fabricated based on the DARPA SUBOFF model with full appendages (configuration 8). Due to the limitation of the towing tank dimension, the SFRM was scaled down. In addition, it is hypothesised that the scale effect has a limited effect on the hydrodynamic forces of the SFRM. Therefore, the dimensionless hydrodynamic coefficients for the vertical and horizontal planes were selected according to the published data and can be summarised in Table 3. Otherwise, the remaining terms in Equations (15)-(20) were set to be zero for simplicity.

Table 3. Hydrodynamic coefficients of the DARPA SUBOFF model.

\begin{tabular}{cccc}
\hline$Z_{w}^{\prime}$ & -0.013910 & $Y_{v}^{\prime}$ & -0.027834 \\
\hline$M_{w}^{\prime}$ & 0.010324 & $N_{v}^{\prime}$ & -0.013648 \\
\hline$Z_{q}^{\prime}$ & -0.007545 & $K_{v}^{\prime}$ & -0.000584 \\
\hline$M_{q}^{\prime}$ & -0.003702 & $Y_{r}^{\prime}$ & 0.005251 \\
\hline$Z_{\dot{w}}^{\prime}$ & -0.014529 & $N_{r}^{\prime}$ & -0.004444 \\
\hline$M_{\dot{w}}^{\prime}$ & -0.000561 & $Y_{\dot{v}}^{\prime}$ & -0.016186 \\
\hline$Z_{\dot{q}}^{\prime}$ & -0.000633 & $N_{\dot{v}}^{\prime}$ & 0.000396 \\
\hline$M_{\dot{q}}^{\prime}$ & -0.000860 & $Y_{\dot{r}}^{\prime}$ & 0.000398 \\
\hline$Z_{\delta_{s}}^{\prime}$ & -0.005603 & $N^{\prime}{ }_{\dot{r}}$ & -0.000897 \\
\hline$M_{\delta_{s}}^{\prime}$ & -0.002409 & $Y^{\prime}{ }_{\delta_{r}}$ & 0.005929 \\
\hline & & $N^{\prime}{ }_{\delta_{r}}$ & -0.002217 \\
\hline & & $K_{\delta_{r}}^{\prime}$ & -0.000005 \\
\hline
\end{tabular}

\section{Autopilot System}

\subsection{Line-of-Sight Guidance Algorithm}

It is demonstrated that the line-of-sight (LOS) guidance algorithm is suitably applied to the surface ships [29]. In addition, the LOS guidance algorithm plays an important role in accurate path tracking control of the AUV [30,31]. Since the path tracking cannot be achieved due to lack of lateral control for the under-actuated AUV, using the LOS guidance algorithm converts the lateral error to the heading movement, which means that the desired path tracking is indirectly achieved by heading control [32].

In this study, the LOS guidance algorithm as shown in Figure 4 was adopted to estimate the desired displacements of the SFRM in the yaw and the pitch modes from the current position to the next waypoint in the earth-fixed coordinate system. The desired yaw and pitch angles can be represented as below:

$$
\begin{aligned}
& \Psi_{d}=\tan ^{-1}\left(\frac{Y_{k}-Y_{C}}{X_{k}-X_{C}}\right), k=1,2, \ldots, n \\
& \theta_{d}=\tan ^{-1}\left(\frac{Z_{k}-Z_{C}}{X_{k}-X_{C}}\right), k=1,2, \ldots, n
\end{aligned}
$$

where both the SFRM's current position $\left(X_{C}, Y_{C}, Z_{C}\right)$ and the next waypoint position $\left(X_{k}, Y_{k}, Z_{k}\right)$ refer to the earth-fixed coordinate system; $\Psi_{d}$ and $\theta_{d}$ denote the desired yaw angle and pitch angle, respectively; and $n$ is the number of waypoints. Subsequently, 
a sphere of acceptance of the LOS guidance algorithm [26] was required for selecting the next waypoint as follows:

$$
\left(X_{k}-X_{C}(t)\right)^{2}+\left(Y_{k}-Y_{C}(t)\right)^{2}+\left(Z_{k}-Z_{C}(t)\right)^{2} \leq R_{0}^{2}
$$

where the allowable radius $R_{0}$ was set to be two times the SFRM's total length $L$ [26].

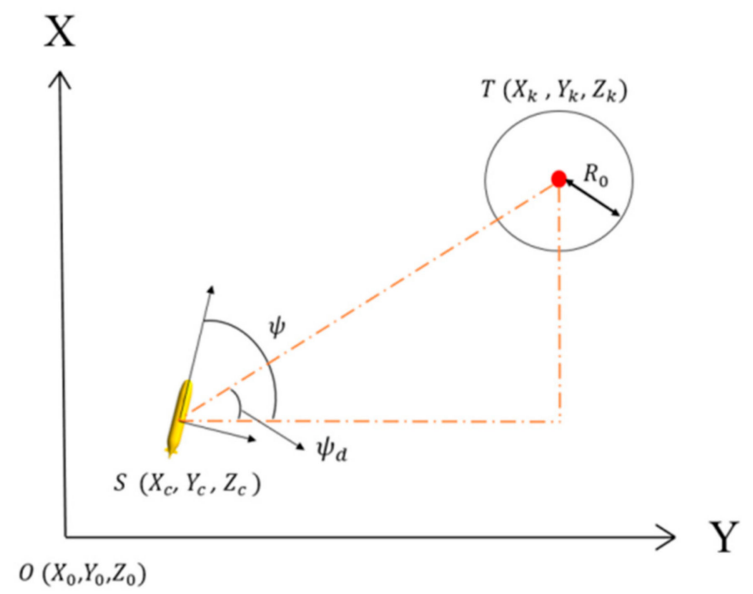

(a)

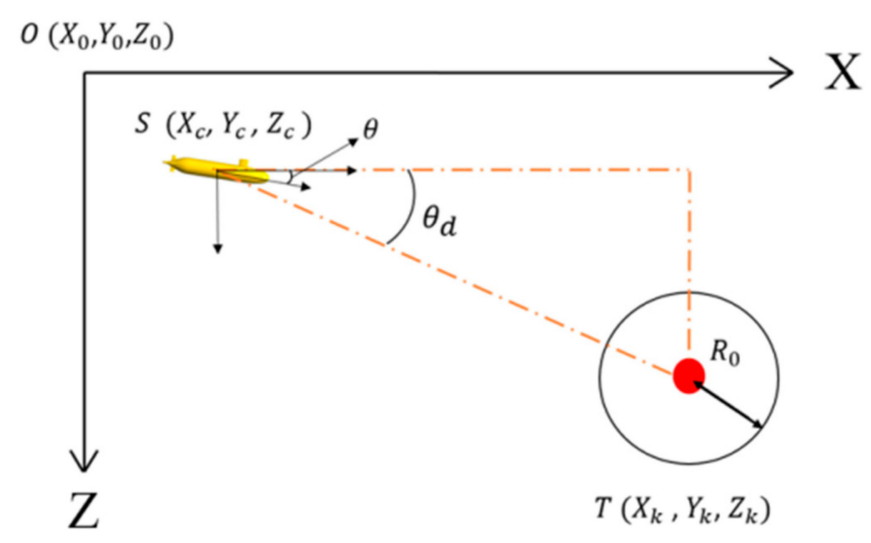

(b)

Figure 4. The schematic diagrams of the line-of-sight (LOS) guidance algorithm in (a) the horizontal plane and (b) the vertical plane, respectively.

\subsection{PD Controller}

In Figure 5, the conventional PD control system is generally introduced in the following equations including two control gains, i.e., proportional gain $\left(K_{P}\right)$ and derivative gain $\left(K_{D}\right)$.

$$
\begin{gathered}
\delta_{V}(t)=K_{P 1}\left(\Psi(t-1)-\Psi_{d}(t-1)\right)+K_{D 1} \dot{\Psi}(t-1) \\
\delta_{H}(t)=K_{P 2}\left(\theta(t-1)-\theta_{d}(t-1)\right)+K_{D 2} \dot{\theta}(t-1)
\end{gathered}
$$

where $\delta_{V}(t)$ and $\delta_{H}(t)$ denote control outputs of the rudder plane angle and the stern plane angle, and they can also be recognised as $\delta_{r}$ and $\delta_{s}$, respectively. $K_{P 1}$ and $K_{D 1}$ are the yaw and yaw rate gains by the rudder plane, whereas $K_{P 2}$ and $K_{D 2}$ are the pitch and pitch rate gains by the stern plane. $\dot{\Psi}(t-1)$ and $\dot{\theta}(t-1)$ imply the yaw rate and pitch rate, respectively.

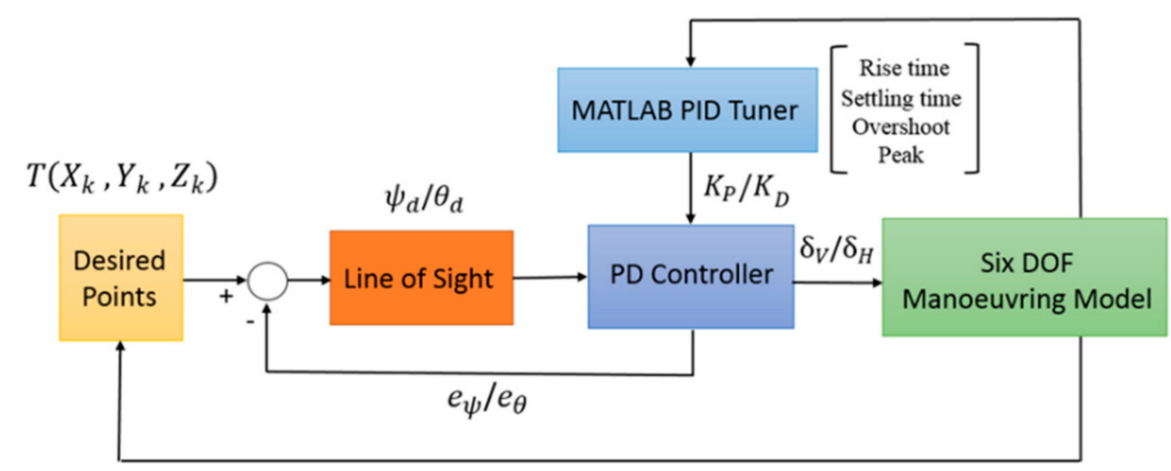

Figure 5. The flow chart of the autopilot system for the submarine free-running model (SFRM) including the LOS guidance algorithm, the PD controller, the PID tuner, and the 6-DOF manoeuvring mathematical model. 
In the control system, the trial-and-error method has been adopted to determine an initial set of control tuning parameters. For an extensive variety of applied methods, it might be the most familiar one. Sometimes, the trial-and-error method does not offer fair tuning and tends to provide an evident overshoot. Hence, it usually needs returning before application. In order to tune the control constraints in demand for an optimal performance, the PID tuner in MATLAB/Simulink [33] has been suggested to achieve the design objectives by means of a balance between robustness and performance. Some important characteristics parameters that need to be considered in the PID tuner are the rise time, settling time, overshoot, and peak, as shown in Figure 6.

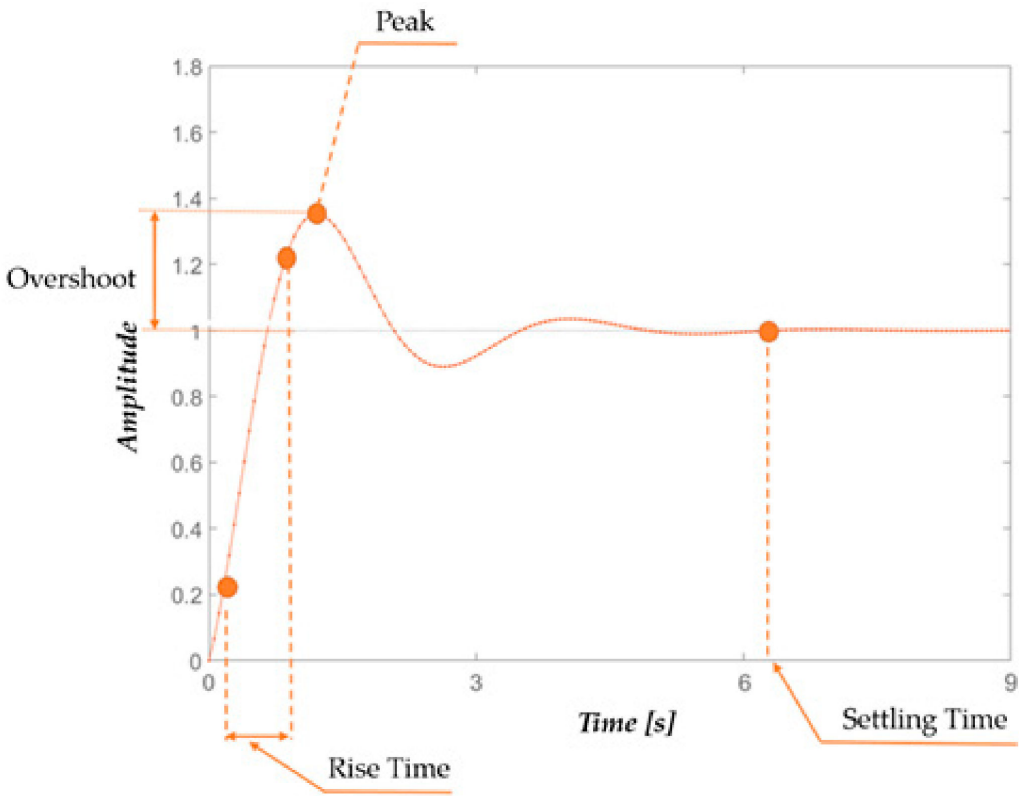

Figure 6. Step response of the PD controller with the PID tuner.

\subsection{Post-Processor}

Figure 7 introduces the post-processor integrated with the autopilot system for the SFRM. In the post-processing process, time histories of the SFRM's trajectories, 6-DOF motion responses, and rudder displacements were presented by conducting the Cinema $4 \mathrm{D}$ modelling [34]. The post-processor, i.e., Cinema 4D modelling, was mainly used to allow the animated model to match the simulated trajectories and courses graphically. At the beginning, point coordinates were sampled on the motion trajectories and then projected on a three-dimensional grid. Subsequently, the path-alignment function was used to simplify the problem of curve alignment, and parallel lines of equal proportions were drawn to fix the whole hull.

Figure $8 \mathrm{a}-\mathrm{f}$ shows each step for the Cinema $4 \mathrm{D}$ modelling after the output results of the SFRM's trajectories and kinematics were computed. Layer-grid setting as shown in Figure 8a begins the initial modelling by adjusting the environment and defining the 3D coordinates. Figure $8 \mathrm{~b}$ presents the modelling-layer setting by which different viewing and ordering methods are applied to layers and labels. Furthermore, the material modules such as color, transparency, and roughness can be selected as illustrated in Figure 8c. Rendering and animation-recording setting as shown in Figure $8 \mathrm{~d}$ determines the pixel aspect ratio in detail when recording animation. Figure 8e implies the setting of animation frame rate and coordinate record point, in which the inputs such as trajectories were presented by adjusting animation frame rate and time. Finally, the animation interface exhibits the real-time motion scenario in the simulated environment, as shown in Figure 8f. 


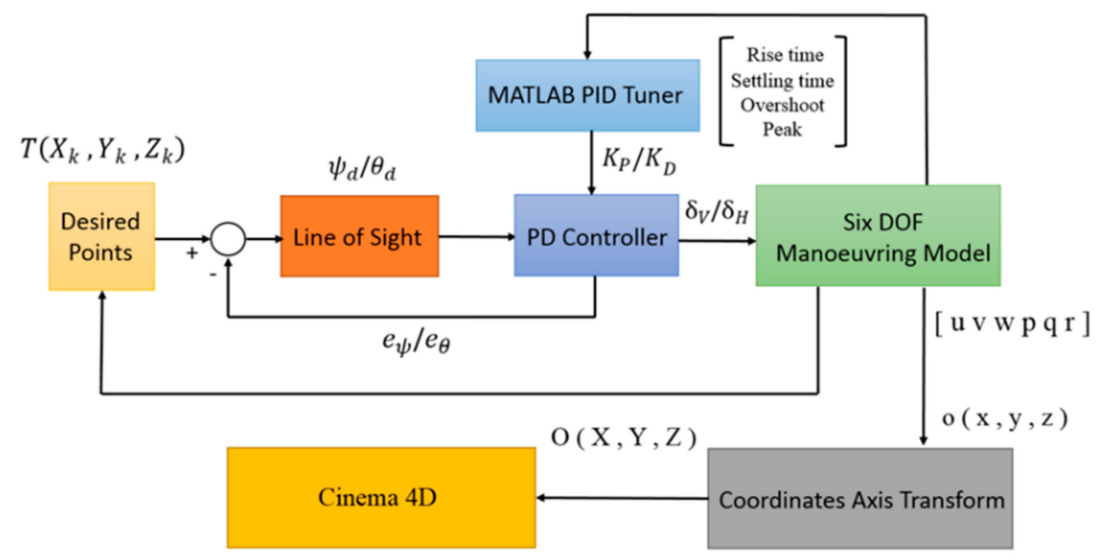

Figure 7. The flow chart of the autopilot system combining with the Cinema 4D modelling.

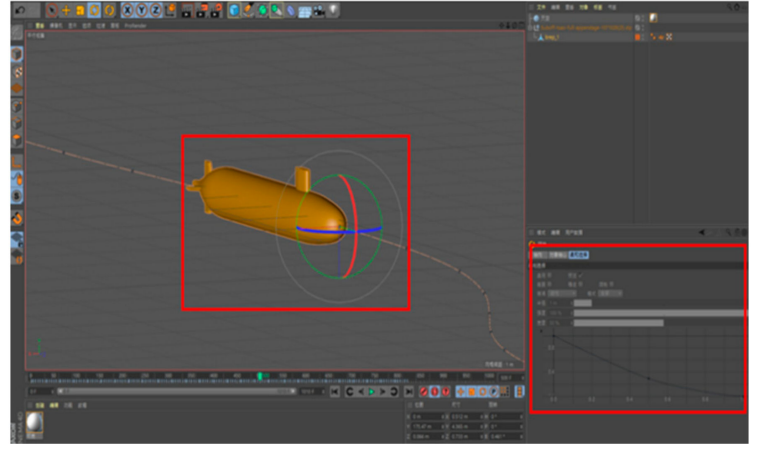

(a)

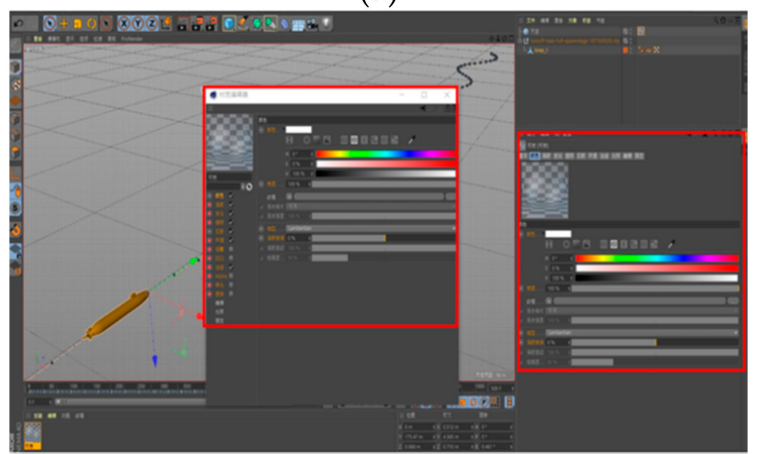

(c)

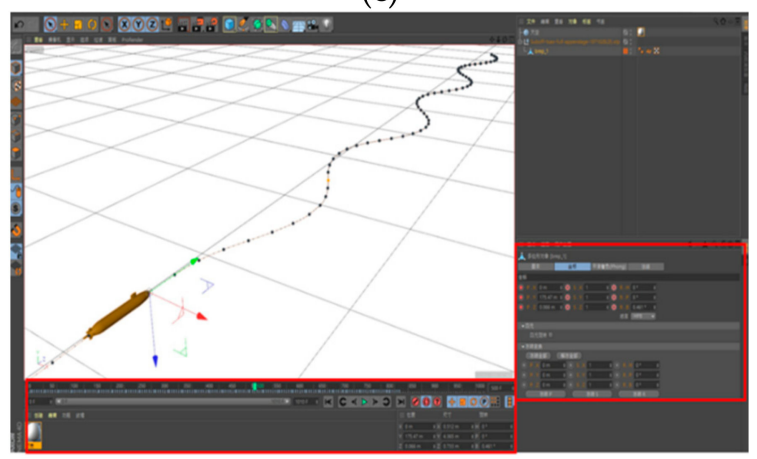

(e)

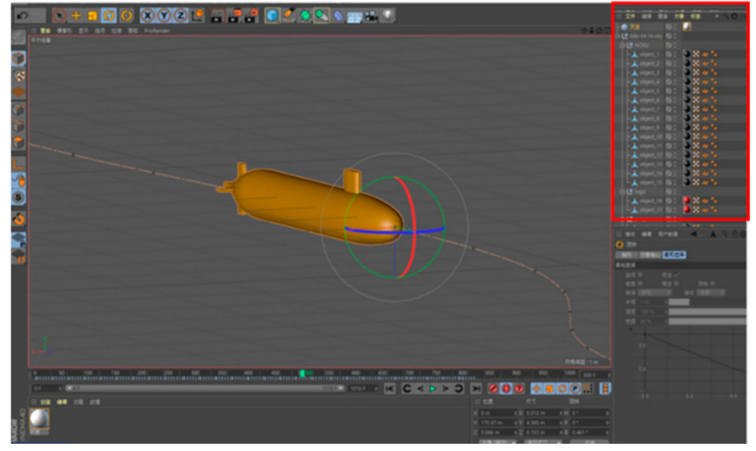

(b)

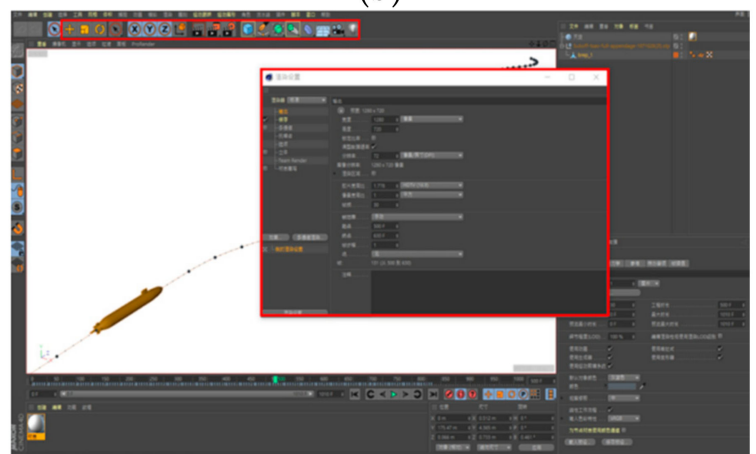

(d)

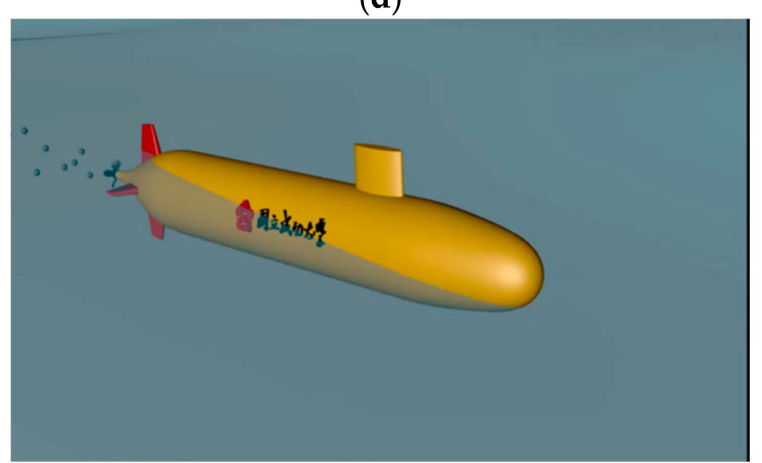

(f)

Figure 8. The operation steps of the Cinema 4D modelling: (a) layer-grid setting, (b) modelling-layer setting, (c) material and texture setting, (d) rendering and animation-recording setting, (e) animation frame rate and coordinate record point setting, and (f) real-time animation interface. 


\section{Results and Discussion}

For understanding the stability of the SFRM, the trim polygon would be illustrated by combining the main ballast tanks and the attitude adjusting system. There were several manoeuvring tests, including the turning circle test, horizontal zigzag test, vertical zigzag test, meander test, and spiral test, which were used for investigating the rudder performance of the SFRM with the empty ballast tanks. Meanwhile, the propeller revolution speed corresponding to each sailing speed is assumed constant. The descriptions of simulation conditions are indicated in Table 4. Subsequently, the optimal control gains on the rudder operations corresponding to the manoeuvring tests in different sailing speeds would be presented by the PID tuner. Lastly, autopilot simulations in a 3D map with numerous waypoints were conducted by adopting different settings of the PD controller.

Table 4. Standard manoeuvring tests for the SFRM.

\begin{tabular}{|c|c|c|}
\hline Test & Purpose & Measured Parameters \\
\hline Trim Polygon & $\begin{array}{c}\text { Determine all the possible changes } \\
\text { in SFRM's mass and } \\
\text { longitudinal CG }\end{array}$ & Mass and trimming moment \\
\hline Turning Circle & $\begin{array}{l}\text { Determine steady turning } \\
\text { performance }\end{array}$ & $\begin{array}{l}\text { Advance, transfer, } \\
\text { and tactical diameter }\end{array}$ \\
\hline Horizontal Zigzag & $\begin{array}{l}\text { Demonstrate course-varying } \\
\text { performance in the horizontal plane }\end{array}$ & $\begin{array}{l}\text { Yaw overshoot, width of path } \\
\text { overshoot, time at which each } \\
\text { change of the rudder plane angle is } \\
\text { initiated, and time to the maximum } \\
\text { width excursion }\end{array}$ \\
\hline Spiral & $\begin{array}{l}\text { Determine control authority and } \\
\text { straight-line stability }\end{array}$ & $\begin{array}{l}\text { Steady yaw rate for } \\
\text { each rudder angle }\end{array}$ \\
\hline Vertical Zigzag & $\begin{array}{l}\text { Demonstrate depth-varying } \\
\text { performance in the vertical plane }\end{array}$ & $\begin{array}{l}\text { Pitch overshoot, width of depth } \\
\text { overshoot, time at which each } \\
\text { change of the stern plane angle is } \\
\text { initiated, and time to the maximum } \\
\text { depth excursion }\end{array}$ \\
\hline Meander & $\begin{array}{l}\text { Determine motion stability and } \\
\text { depth keeping performance }\end{array}$ & Path of the SFRM \\
\hline
\end{tabular}

\subsection{Trim Polygon}

Similar to the arrangement of a submarine, the SFRM ought to have several types of ballast tanks. The main ballast tanks are designed for diving and surfacing, whereas the trimming tanks are used for adjusting the submarine's attitude on the surface or underwater. Due to the limitation of the compartment space in the scale model, the trimming tanks were replaced by the attitude adjusting system without water compensation. Specifically, the design of the attitude adjusting system is a slider mechanism device installed in the midsection for adjusting the trim angle.

Figure 9 presents the time series of the mass changes in the forward and aft ballast tanks, respectively. Both the inflow and outflow rates were given as $20 \mathrm{~cm}^{3} / \mathrm{s}$ during the periods of 20 to $50 \mathrm{~s}$ and 70 to $100 \mathrm{~s}$. Figure 10 exhibits the time series of the corresponding pitch angles in the forward and aft ballast tanks, respectively.

Apparently, the maximum pitch angle of the SFRM reached $-8^{\circ}$ when the forward ballast tank was full. There were some oscillations accompanied by the variation of the pitch angle. For the aft ballast tank, by using the same mass-variation history of the forward ballast tank, the maximum pitch angle of the SFRM reached $5^{\circ}$ with slight oscillations. 


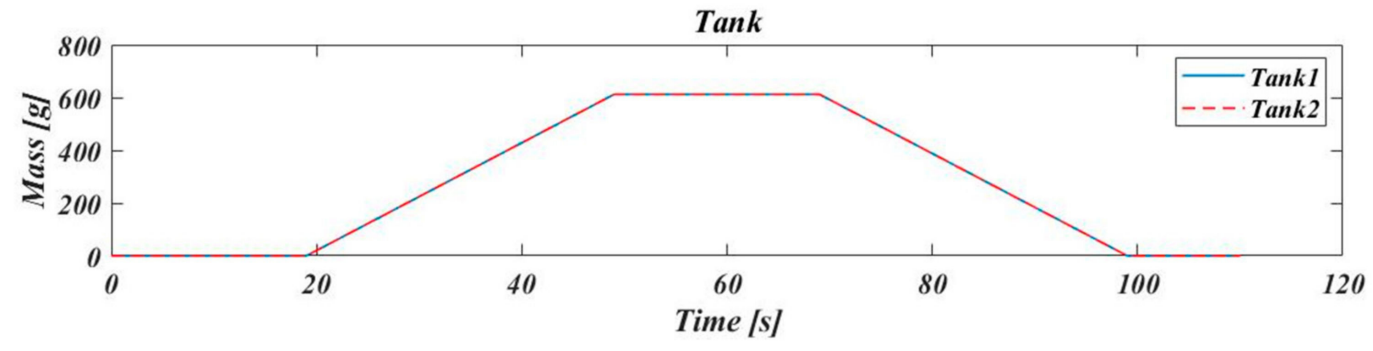

Figure 9. Time series of the mass changes in the forward and aft ballast tanks, respectively.

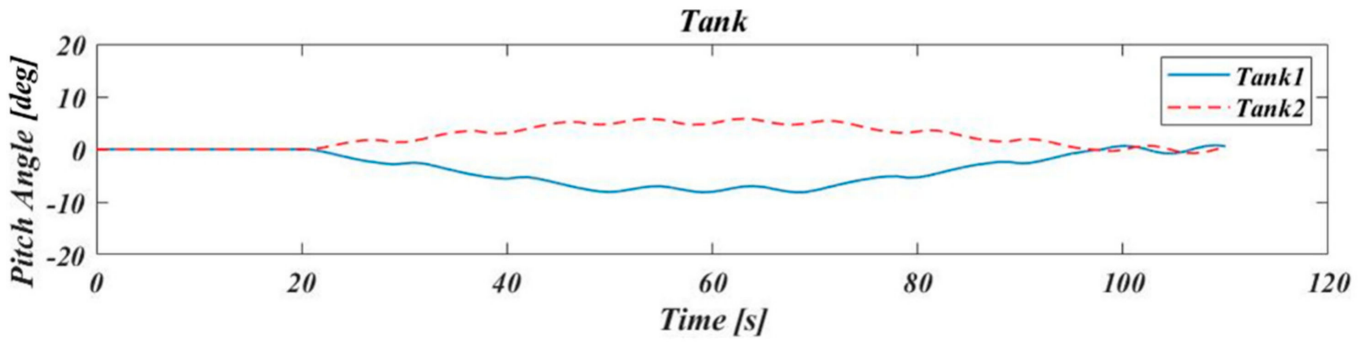

Figure 10. Time series of the corresponding pitch angles in the forward and aft ballast tanks, respectively.

Figure 11 shows a typical trim polygon (equilibrium polygon), which is useful to assess the arrangement of the SFRM. Definitely, it is crucial to determine whether the ballast tanks and the attitude adjusting system are available to estimate the variation of SFRM's mass and the longitudinal CG. According to the procedure [35], the effects of the ballast tanks and the attitude adjusting system can be plotted as a function of mass and trimming moment as follows:

0 In the initial stage, the location with zero mass and zero trimming moment indicated all empty tanks and a zero pitch angle.

1 Move forward the weight of the slider mechanism device. In this stage, there is no mass variation, but there is an increase of trimming moment due to the movement of the longitudinal CG.

2 The forward ballast tank is filled completely. There are increases in mass and trimming moment due to moving forward of the longitudinal CG.

3 The aft ballast tank is filled completely. This is continued until the previous procedure has been completed. There is an increase in mass but a slight decrease in trimming moment due to moving backward of the longitudinal CG.

4 Move the weight of the slider mechanism device to the initial location. There is no change in mass, but there is a slight difference in trimming moment compared with the line in step 1 . When both of the ballast tanks are full, the slight forward of the longitudinal CG causes a small forward trimming moment.

5 Move backward the weight of the slider mechanism device. The mass is still kept the same as the one in step 4 , but the variation of the trimming moment is even less than the one in step 4.

6 The forward ballast tank is completely empty. There are decreases in mass and trimming moment due to moving backward of the longitudinal CG. The variation of mass is the same as the one in step 3, but the variation of the trimming moment is even larger than the one in step 3.

7 The aft ballast tank is completely empty. There is a decrease in mass, but an increase in trimming moment due to the moving forward of the longitudinal CG. The variation of mass is the same as the one in step 2, but the variation of the trimming moment is even smaller than the one in step 2. 
8 Move the weight of the slider mechanism device to the initial location. When all the ballast tanks are empty, the line has returned to the initial location with zero mass and zero trimming moment.

\section{Trim Polygon}

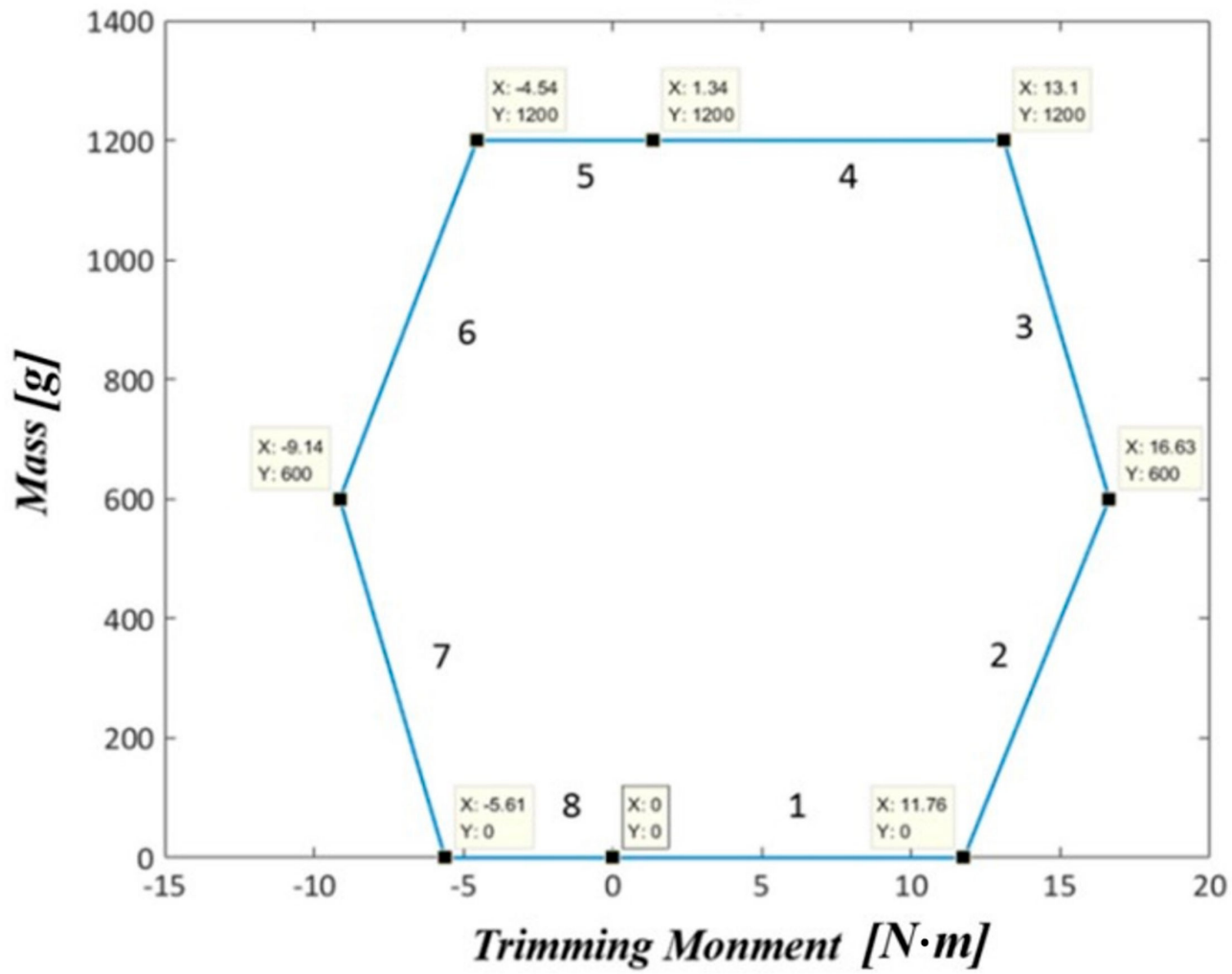

Figure 11. The trim polygon of the SFRM.

Finally, the results of the trim polygon by adopting the above-mentioned procedure were introduced in Table 5.

Table 5. Variations of trimming moment and mass in different steps.

\begin{tabular}{ccc}
\hline Step & Trimming Moment $[\mathbf{N} \cdot \mathbf{m}]$ & Mass $[\mathrm{g}]$ \\
\hline 0 & 0 & 0 \\
\hline 1 & 11.76 & 0 \\
\hline 2 & 16.63 & 600 \\
\hline 3 & 13.1 & 1200 \\
\hline 4 & 1.34 & 1200 \\
\hline 5 & -4.54 & 1200 \\
\hline 6 & -9.14 & 600 \\
\hline 7 & -5.61 & 0 \\
\hline 8 & 0 & 0 \\
\hline
\end{tabular}

\subsection{Manoeuvring Tests}

\subsubsection{Turning Circle Test}

When the rudder angle was given a constant value, the SFRM would run in a circle with the direction of its course changing $360^{\circ}$. In the turning circle test, the tactical diameter, advance, transfer, drift angle, and speed loss can be measured. At the beginning, the SFRM 
sailed straight for $100 \mathrm{~s}$. Subsequently, the rudder was then pulled to $20^{\circ}$ immediately for another $100 \mathrm{~s}$ for a total simulation time of $200 \mathrm{~s}$. In the turning circle test, the exact turning time of the rudder was set to be $1 \mathrm{~s}$.

The main purpose of the turning circle test was to evaluate the turning performance of the SFRM. Figure 12 compares the trajectories of the simulated SFRM at three sailing speeds: $U=0.5,1$, and $1.5 \mathrm{~m} / \mathrm{s}$. It is clearly found that the straight parts of these three trajectories are not coincident due to the variation of the critical point [35], which will affect the pitch angle and the straight-line stability. When executing the turning circle tests, the advances of the SFRM are $44.8,95$, and $145.6 \mathrm{~m}$, corresponding to three sailing speeds, i.e., $U=0.5,1$, and $1.5 \mathrm{~m} / \mathrm{s}$. On the other hand, the transfers are identical to $4.61,4.52$ and $4.47 \mathrm{~m}$, whereas the tactical diameters are $9.79,9.77$, and $0.68 \mathrm{~m}$, respectively. In contrast to advance, both transfer and tactical diameter become small with the increase of the sailing speed.

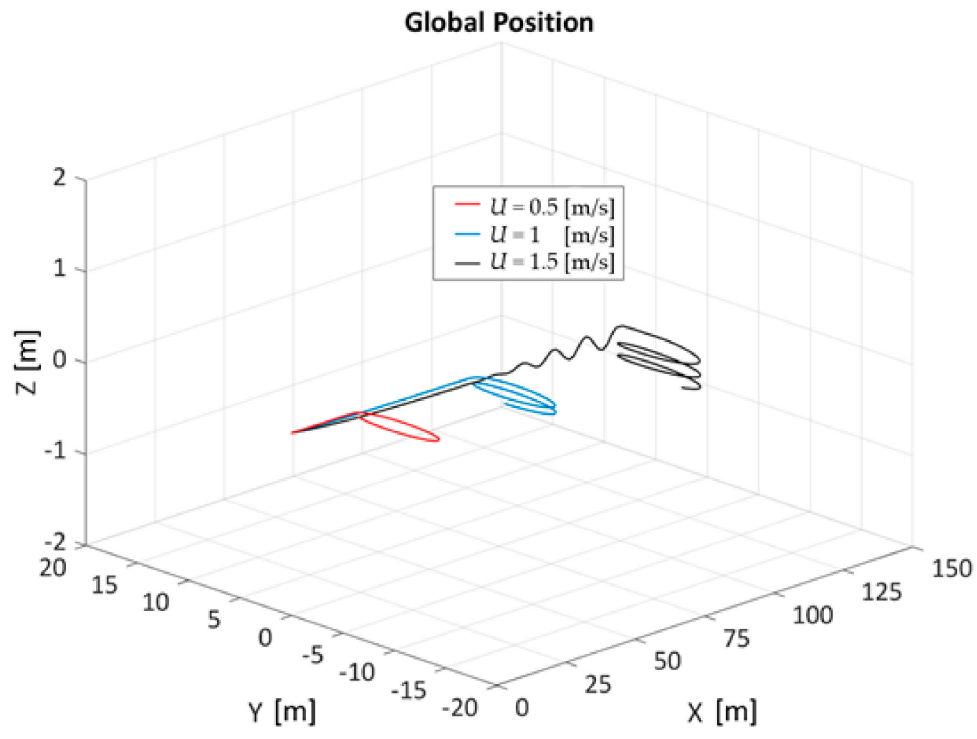

Figure 12. The SFRM's trajectories at different sailing speeds in the turning circle test.

When the speed was near $1.5 \mathrm{~m} / \mathrm{s}$, the SFRM started to exhibit slight vertical vibrations. It is obvious that the distance and trajectory of the SFRM were evidently affected by the sailing speed. With the increase of the sailing speed, the trajectory's vertical vibration becomes evident due to the increase of hydrodynamic trimming moment.

Figure 13 presents the time series of velocity components at different sailing speeds in each degree of freedom, including surge $(u)$, sway $(v)$, heave $(w)$, roll $(p)$, pitch $(q)$, and yaw rates $(r)$. The variations of the 6-DOF velocity components were found to be dominated by the sailing speeds. This was particularly evident after the rudder was steered, as lateral resistance caused a considerable decrease in surge velocity (Figure 13a). Additionally, different speed settings caused the heave velocity and the pitch velocity in Figure 13c,e, respectively, to undulate slightly when the sailing speed grew high but remained rather stable when the sailing speed was low. 


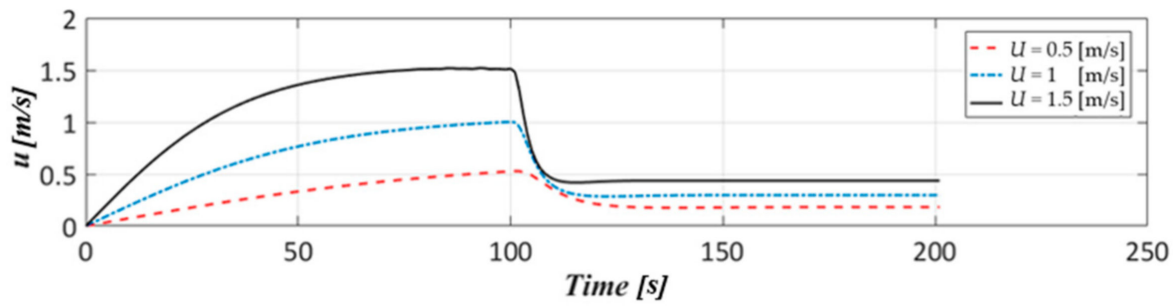

(a)

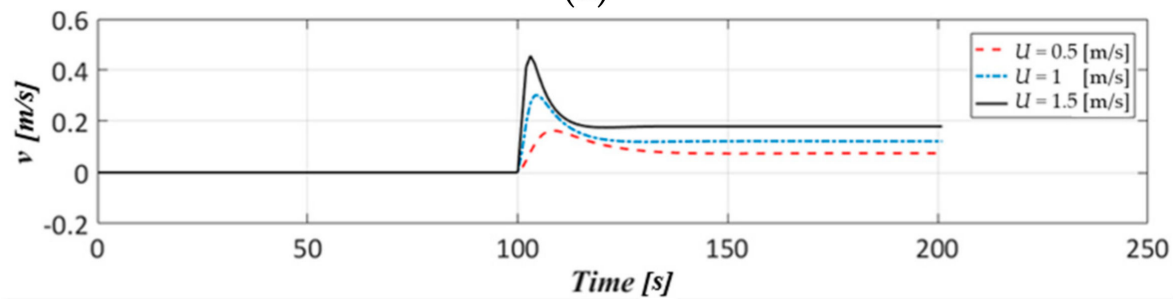

(b)

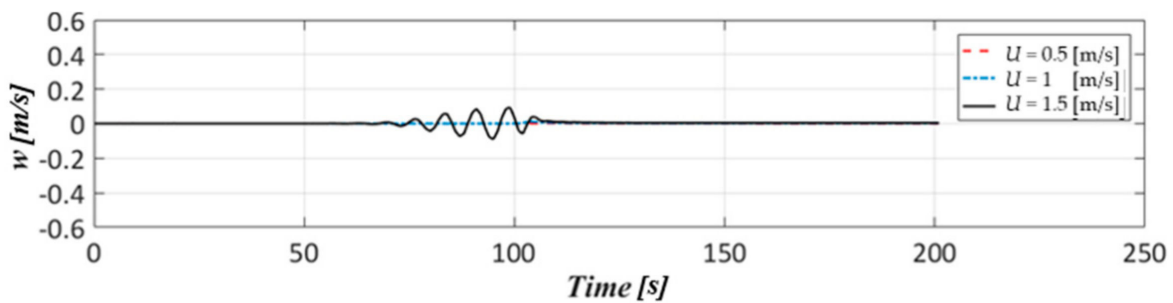

(c)

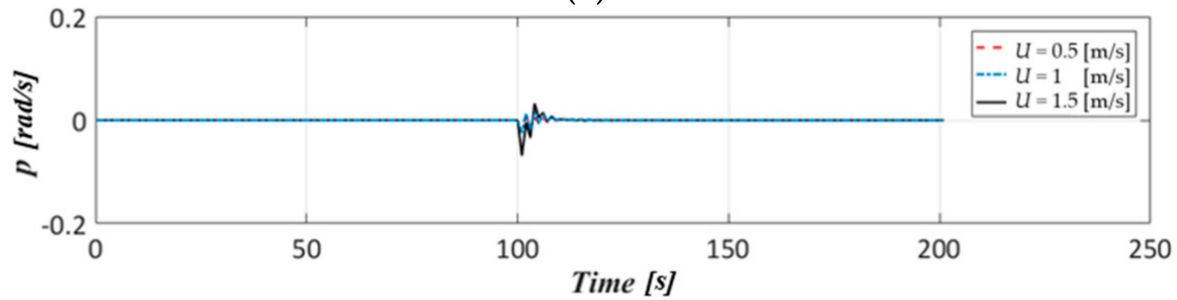

(d)

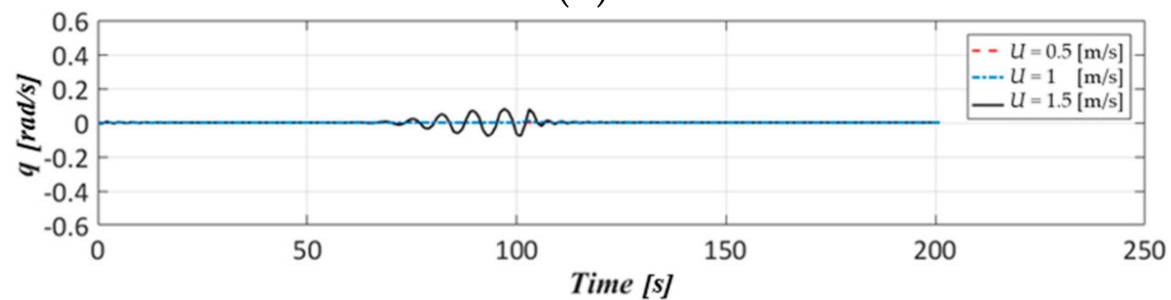

(e)

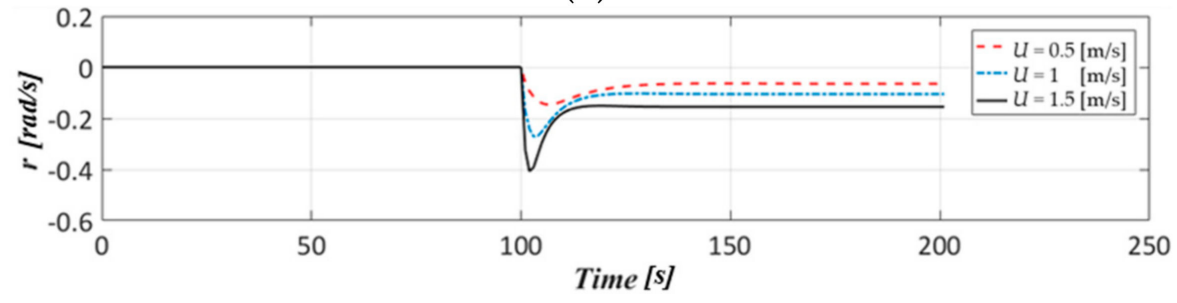

(f)

Figure 13. Time series of 6-DOF velocity components during the turning circle test at different sailing speeds. (a) Surge rate: $u[\mathrm{~m} / \mathrm{s}],(\mathbf{b})$ sway rate: $v[\mathrm{~m} / \mathrm{s}],(\mathbf{c})$ heave rate: $w[\mathrm{~m} / \mathrm{s}],(\mathbf{d})$ roll rate: $p[\mathrm{rad} / \mathrm{s}]$, (e) pitch rate: $q[\mathrm{rad} / \mathrm{s}]$, and (f) yaw rate: $r[\mathrm{rad} / \mathrm{s}]$. 


\subsubsection{Horizontal Zigzag Test}

In the horizontal zigzag test, the rudder planes were immediately pulled to a fixed angle $\left(\delta_{V}\right)$ and remained in that position until the desired course angle $\left(\Psi_{d}\right)$ of the SFRM is reached; then, the rudder was pulled to the counter rudder angle $\left(-\delta_{V}\right)$ immediately and remained in that position until the desired course angle turned to $-\Psi_{d}$. Specifically, different rudder angles $(\delta)$ and course (yaw) angles ( $\Psi$ ) were experimented on in the test. The course overshooting angle and the time required to reach maximum overshooting within the duration of each rudder angle change were measured to determine the SFRM's manoeuvrability in course change. In the simulation, the SFRM sailed straight for $100 \mathrm{~s}$. Then, the rudder plane was immediately turned to $20^{\circ}$, and the position of the rudder plane was maintained for a certain period. When the yaw angle reached $20^{\circ}$, the rudder plane was immediately turned to $-20^{\circ}$, and the position of the rudder plane was maintained for a certain period. After the yaw angle changed to $-20^{\circ}$, the previous procedure was repeated. In the horizontal zigzag test, the exact turning time of the rudder was set to be $1 \mathrm{~s}$. Meanwhile, the maintaining time of the rudder angle at $\pm 20^{\circ}$ was given as 15,8 , and $6 \mathrm{~s}$ for $U=0.5,1$, and $1.5 \mathrm{~m} / \mathrm{s}$, respectively.

Figure 14 compares the SFRM's trajectories (top view) at three different sailing speeds: $U=0.5,1$, and $1.5 \mathrm{~m} / \mathrm{s}$, respectively. When $U=1.5 \mathrm{~m} / \mathrm{s}$, the trajectory was significantly longer than those of $U=1 \mathrm{~m} / \mathrm{s}$ and $U=0.5 \mathrm{~m} / \mathrm{s}$. Additionally, the yawing amplitude (width of the path overshoot) was found to be larger for the case of the faster sailing speed and varied according to different periods of the rudder operations. For $U=0.5,1$, and $1.5 \mathrm{~m} / \mathrm{s}$, the yawing amplitudes are $0.89,2.07$, and $3.36 \mathrm{~m}$. The trajectory of the SFRM at the highest sailing speed is not straight due to the slight variation of yaw overshoot in the subsequent horizontal zigzag maneouvres.

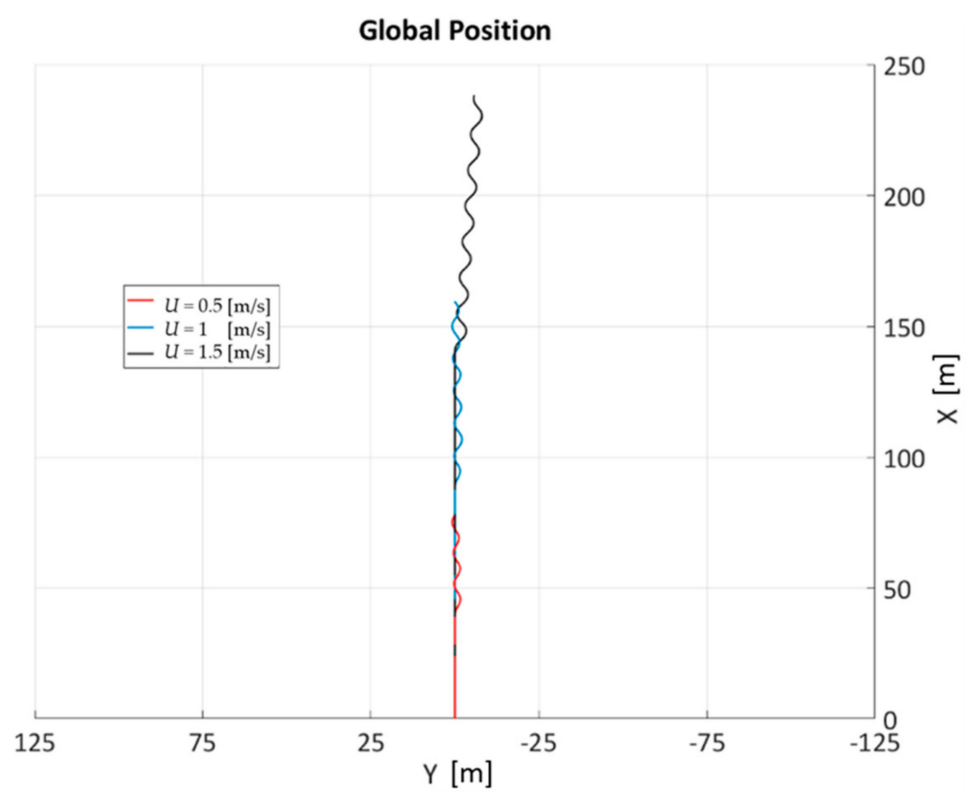

Figure 14. The SFRM's trajectories in the horizontal zigzag test at different sailing speeds.

Figure 15a-c presents the time series of rudder and yaw angles at different sailing speeds. Figure $15 \mathrm{a}$ indicates that when $U=0.5 \mathrm{~m} / \mathrm{s}$, a full cycle of turning the yaw angle from $0^{\circ}$ to $-20^{\circ}$ and then $20^{\circ}$ required $21 \mathrm{~s}$. Figure $15 \mathrm{~b}$ illustrates that when $U=1 \mathrm{~m} / \mathrm{s}$, a full turning cycle was $11 \mathrm{~s}$ long. Finally, Figure $15 \mathrm{c}$ indicates that when $U=1.5 \mathrm{~m} / \mathrm{s}$, a full turning cycle was $9 \mathrm{~s}$ long. Specifically, the time to the maximum width excursion of the first overshoot from the initial operation of the rudder planes required 7,4 , and $3 \mathrm{~s}$ for $U=0.5,1.0$, and $1.5 \mathrm{~m} / \mathrm{s}$. On the other hand, time to the maximum width excursion of the second overshoot from the initial operation of the rudder planes required 21, 11, and $9 \mathrm{~s}$ for $U=0.5,1.0$, and $1.5 \mathrm{~m} / \mathrm{s}$. 


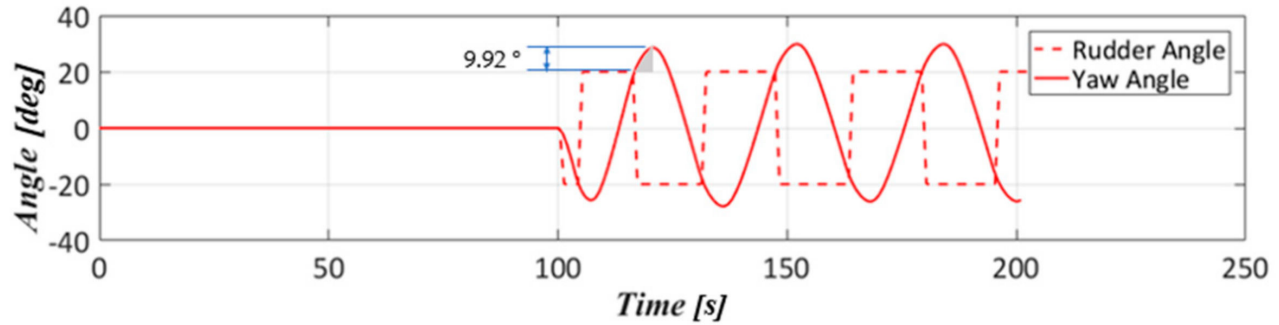

(a)

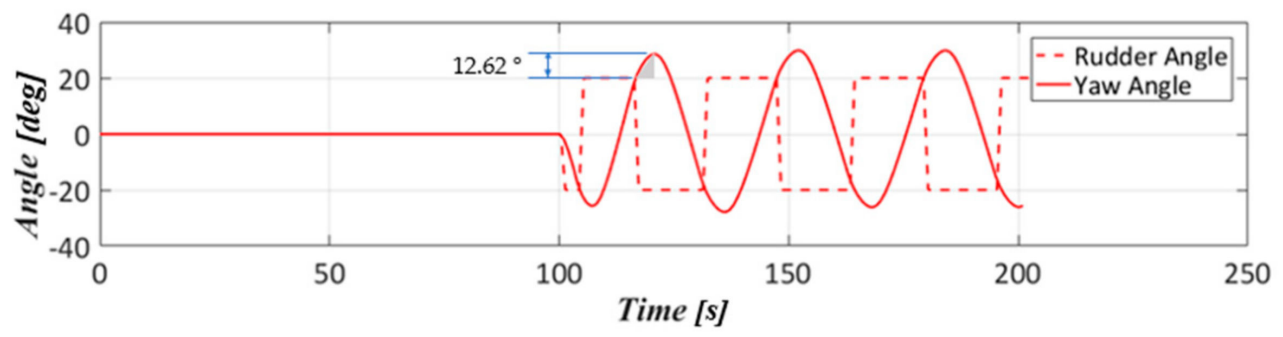

(b)

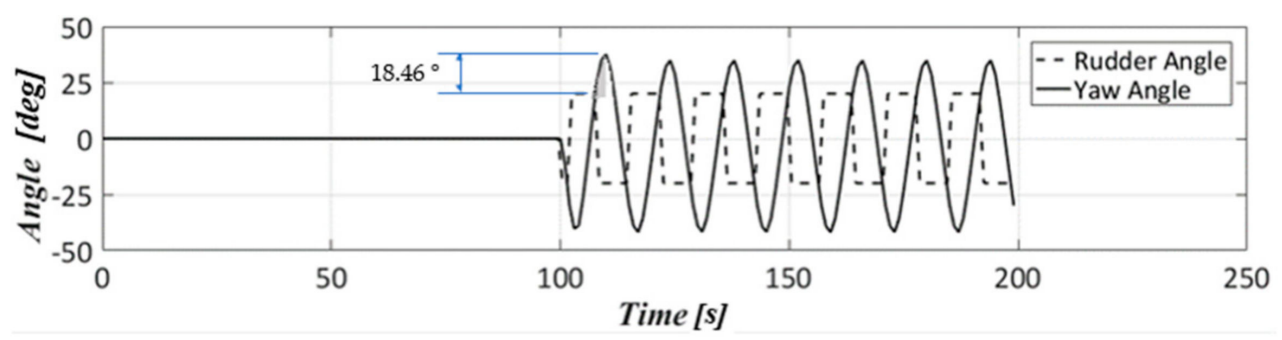

(c)

Figure 15. Time series of rudder and yaw angles at (a) $U=0.5 \mathrm{~m} / \mathrm{s},(\mathbf{b}) U=1 \mathrm{~m} / \mathrm{s}$, and (c) $U=1.5 \mathrm{~m} / \mathrm{s}$. The maximum overshooting angle is highlighted by the gray area.

The SFRM's reaction speed increased considerably at higher sailing speeds. In terms of overshooting angles, Figure 15 a indicates that when $U=0.5 \mathrm{~m} / \mathrm{s}$, the maximum overshooting angle was $9.92^{\circ}$. In Figure $15 \mathrm{~b}$, when $U=1 \mathrm{~m} / \mathrm{s}$, the maximum overshooting angle was $12.62^{\circ}$. Finally, Figure $15 \mathrm{c}$ indicates that when $U=1.5 \mathrm{~m} / \mathrm{s}$, the maximum overshooting angle was $18.46^{\circ}$. The overshooting angle increased considerably in accordance with higher speeds. Given that the time at which the deflection of rudder angle is initiated is the same, i.e., $t=100 \mathrm{~s}$, the time to the maximum width excursion of the yaw angle is shorter for the higher speed than that for the lower speed. Additionally, more turning cycles were completed at higher speeds than at lower speeds. Therefore, sailing speed was found to be a critical parameter influencing the relationship between yaw angle, rudder angle, and overshooting angle.

Figure 16a-f display the time series of surge $(u)$, sway $(v)$, heave $(w)$, roll $(p)$, pitch $(q)$, and yaw rates $(r)$ at different sailing speeds and corresponding amplitude changes. In the horizontal zigzag test, the relationship between rudder angle and course angle was analysed. Accordingly, the velocities and angular velocities in the six degrees of freedom exhibited more significant changes when $U=1.5 \mathrm{~m} / \mathrm{s}$ than when $U=1$ and $0.5 \mathrm{~m} / \mathrm{s}$. In Figure $16 \mathrm{c}, \mathrm{e}$, when the sailing speed reaches close to $1.5 \mathrm{~m} / \mathrm{s}$, some vertical vibrations will begin to appear in the heave and pitch rates. 


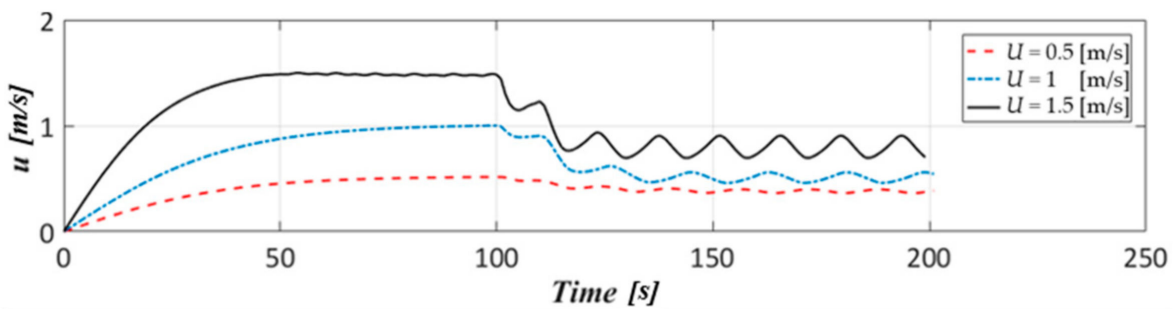

(a)

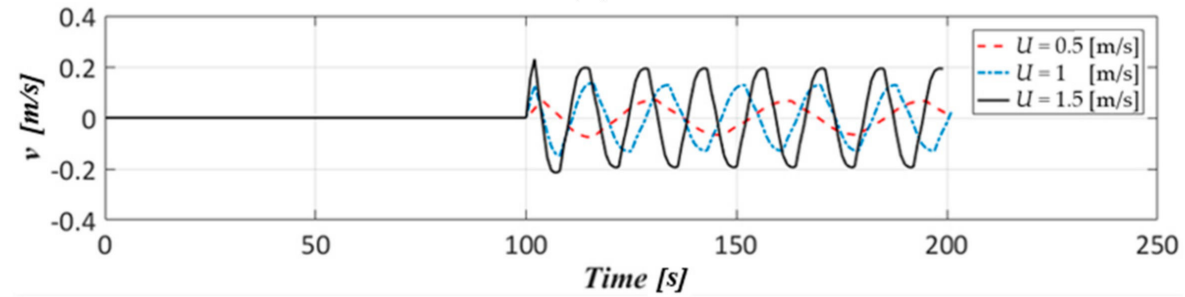

(b)

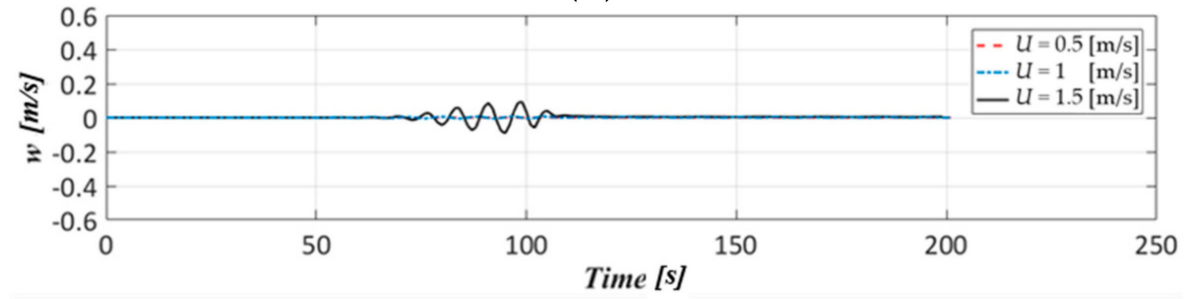

(c)

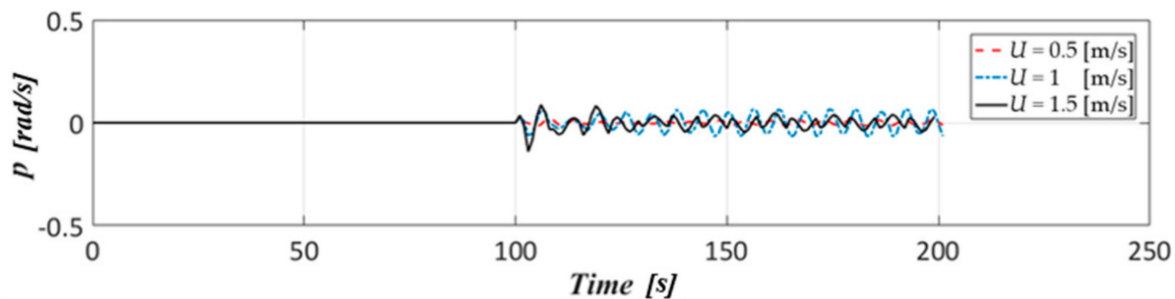

(d)

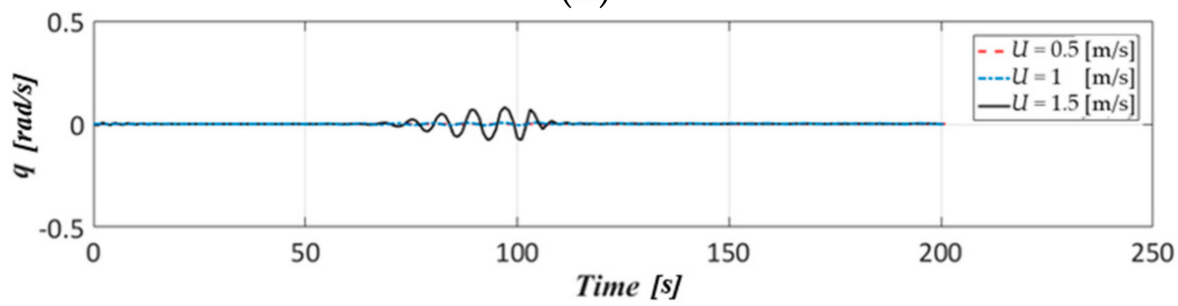

(e)

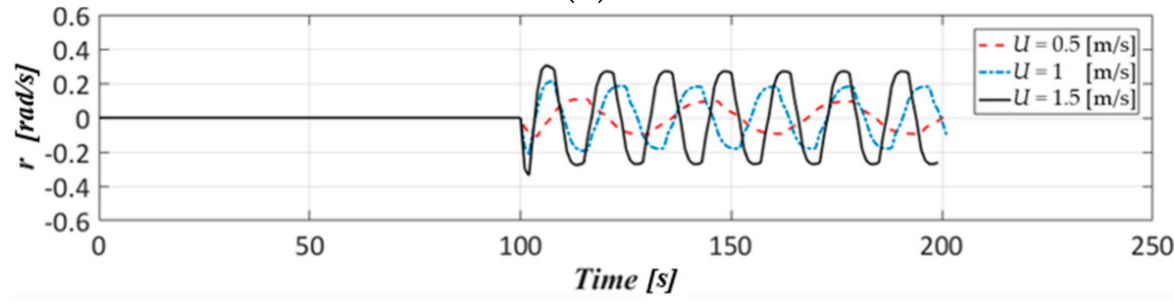

(f)

Figure 16. 6-DOF velocity components in the horizontal zigzag test at different sailing speeds. (a) Surge rate: $u[\mathrm{~m} / \mathrm{s}]$, (b) sway rate: $v[\mathrm{~m} / \mathrm{s}],(\mathbf{c})$ heave rate: $w[\mathrm{~m} / \mathrm{s}],(\mathbf{d})$ roll rate: $p[\mathrm{rad} / \mathrm{s}],(\mathbf{e})$ pitch rate: $q[\mathrm{rad} / \mathrm{s}]$, and (f) yaw rate: $r[\mathrm{rad} / \mathrm{s}]$. 


\subsubsection{Spiral Test}

The main purpose of the spiral test was to evaluate the SFRM's ability to control the rudder plane and maintain linear stability. In the simulation, the rudder plane was immediately pulled to a certain angle, e.g., $25^{\circ}$, and the angle was gradually reduced until the stable yaw rate was reached. This was repeated to identify the relationship between the rudder plane angle and the yaw rate. Figure 17 illustrates the distributions of the spiral tests for different rudder plane angles at three sailing speeds: $U=0.5,1$, and $1.5 \mathrm{~m} / \mathrm{s}$. Specifically, Figure 17 displays changes in yaw rate and rudder plane angles when the rudder plane was gradually reduced from $25^{\circ}$ to $-25^{\circ}$ by $5^{\circ}$ each time. From the simulation results, the yaw rate exhibited a relatively linear trend with different rudder plane angles and sailing speeds. For example, a larger rudder plane angle indicated a faster yaw rate. In other words, it explained that the yaw rate at each increment is dependent on the initial sailing speed. The trend also revealed that for small rudder angles, the rate of turn would depend upon whether the rudder angle is increasing or decreasing [36], especially in case of high sailing speed.

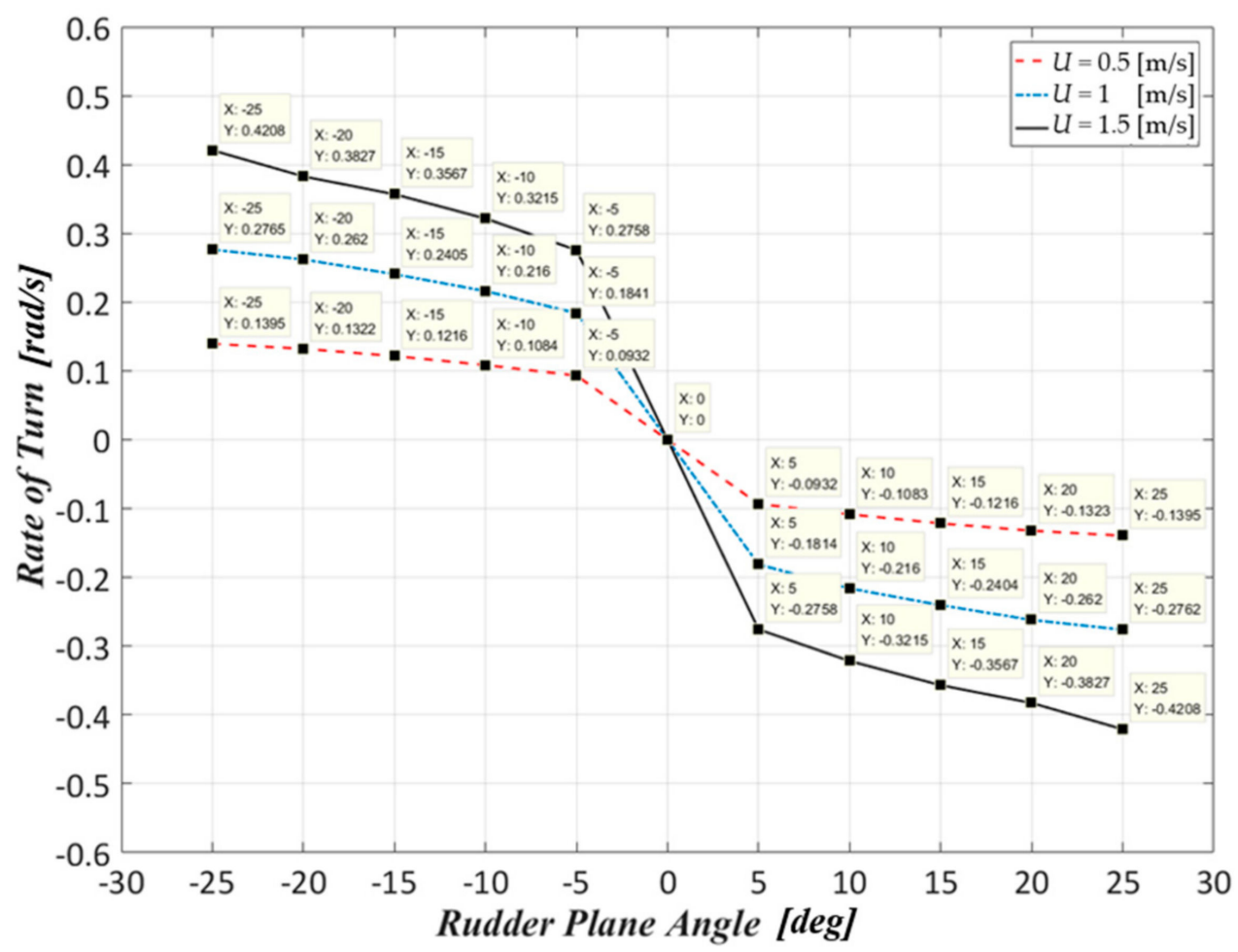

Figure 17. Relationships between the yaw rates and the rudder plane angles at different sailing speeds for the spiral test.

\subsubsection{Vertical Zigzag Test}

In the vertical zigzag test, the stern planes were pulled to a fixed angle $\left(\delta_{H}\right)$, and its position was maintained until the desired pitch angle $\left(\theta_{d}\right)$ was reached before the stern planes were pulled to the counter angle $\left(-\delta_{H}\right)$ and maintained until the desired pitch angle of the SFRM reached $-\theta_{d}$. Different stern plane angles $(\delta)$ and pitch angles $(\theta)$ were experimented on in the test. The overshooting angle of each pitch movement, the width of depth overshoot, and time to the maximum depth excursion of each stern plane angle change were measured to determine the SFRM's manoeuvrability in depth change. Vertical zigzag manoeuvre is widely used to evaluate the manoeuvrability of submarines, so this can be definitely used to evaluate the manoeuvrability of the SFRM. In the simulation, the SFRM first sailed straight for $100 \mathrm{~s}$; then, the stern planes were turned to $20^{\circ}$, and its position was maintained for a certain period. When the pitch angle reached $20^{\circ}$, the stern plane was immediately turned to $-20^{\circ}$, and its position was maintained for a certain period. When the pitch angle reached 
$-20^{\circ}$, the procedure was repeated. However, the pitch overshoot was reached only in case of $U=1.5 \mathrm{~m} / \mathrm{s}$. For comparison, the stern plane operations of $U=0.5$ and $1.0 \mathrm{~m} / \mathrm{s}$ were set to be the same as the ones of $U=1.5 \mathrm{~m} / \mathrm{s}$. In the vertical zigzag test, the exact turning time of the stern plane was set to be $1 \mathrm{~s}$. In addition, the maintaining time of the stern plane angle at $\pm 20^{\circ}$ was all given as $6 \mathrm{~s}$ for $U=0.5,1$, and $1.5 \mathrm{~m} / \mathrm{s}$.

Figure 18 compares the SFRM's trajectories in the vertical zigzag test at sailing speeds of $U=0.5,1$, and $1.5 \mathrm{~m} / \mathrm{s}$. When $U=1.5 \mathrm{~m} / \mathrm{s}$, the trajectory was significantly longer than those of $U=1 \mathrm{~m} / \mathrm{s}$ and $U=0.5 \mathrm{~m} / \mathrm{s}$. When $U=1.5 \mathrm{~m} / \mathrm{s}$, the trajectory was significantly longer than those of $U=1 \mathrm{~m} / \mathrm{s}$ and $U=0.5 \mathrm{~m} / \mathrm{s}$. The pitching amplitude (width of the depth overshoot) was found to be larger for the case of the faster sailing speed and varied according to different periods of the stern plane operations. For $U=0.5,1$, and $1.5 \mathrm{~m} / \mathrm{s}$, the pitching amplitudes are $0.44,0.48$, and $1.14 \mathrm{~m}$. The SFRM moved significantly farther at higher speeds, and a slight pitch motion occurred due to the movement of the critical point [35]. In addition, the simulated trajectories and time between stern plane position changes varied at different sailing speeds.

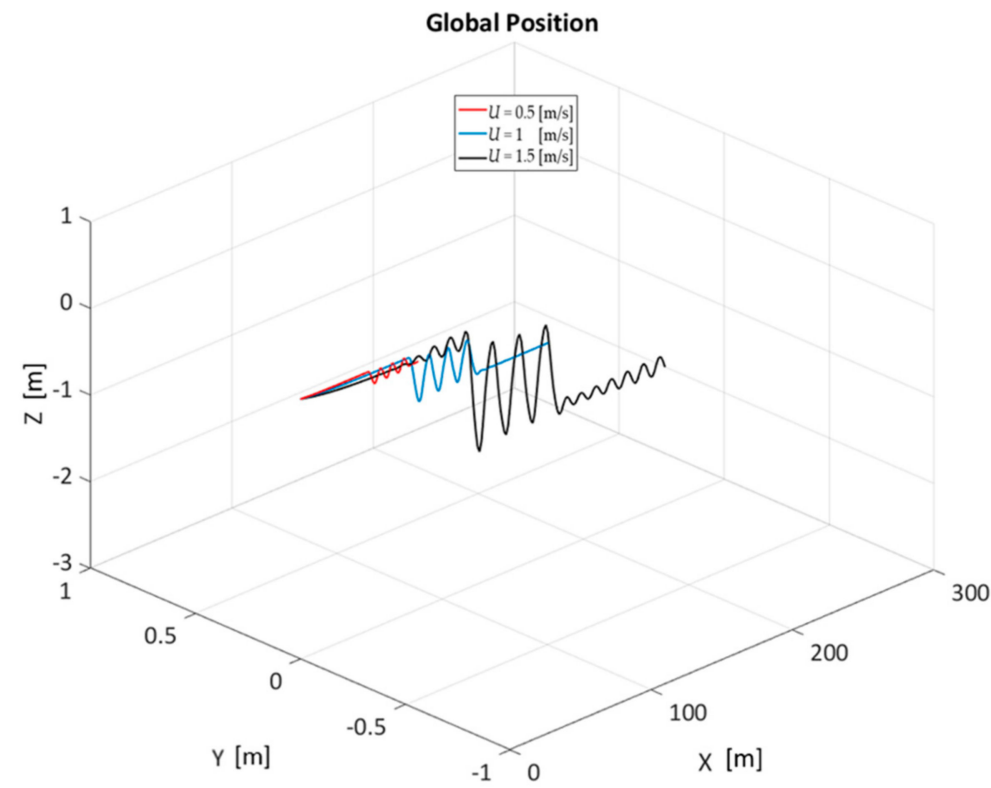

Figure 18. The SFRM's trajectories in the vertical zigzag test at different sailing speeds.

Figure 19a-c illustrates the variations of time series in stern plane and pitch angles at three sailing speeds. A full cycle of turning the pitch angle from $0^{\circ}$ to $-20^{\circ}$ and then $20^{\circ}$ required $10 \mathrm{~s}$. Specifically, time to the maximum depth excursion of the first overshoot from the initial operation of the stern planes required $4 \mathrm{~s}$. On the other hand, time to the maximum depth excursion of the second overshoot from the initial operation of the stern planes required $10 \mathrm{~s}$.

In terms of overshooting angles, Figure 19 a indicates that when $U=0.5 \mathrm{~m} / \mathrm{s}$, the maximum overshooting angle was $-14.15^{\circ}$. In Figure 19b, the maximum overshooting angle was $-6.94^{\circ}$ when $U=1 \mathrm{~m} / \mathrm{s}$. Finally, Figure $19 \mathrm{c}$ demonstrates that when $U=1.5 \mathrm{~m} / \mathrm{s}$, the maximum overshooting angle was $2.1^{\circ}$. Therefore, at high sailing speeds, the maximum overshooting angle of the SFRM increased significantly compared with that at lower sailing speeds. Given that the stern-plane operation period is the same, the vertical zigzag movement is verified to be highly correlated with sailing speed. Since the variation of ballast tanks has an influence on the vertical zig-zag test, the changes in the vehicle's weight, CG, buoyancy center, and moment of inertia must be considered in future work, in addition to the two aforementioned factors. 


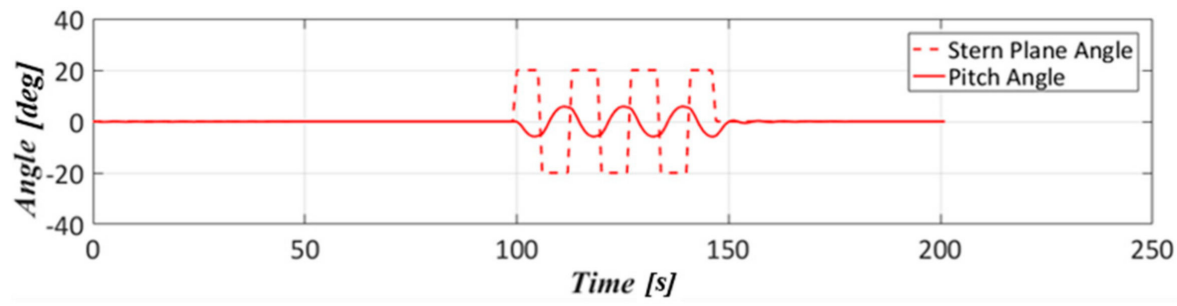

(a)

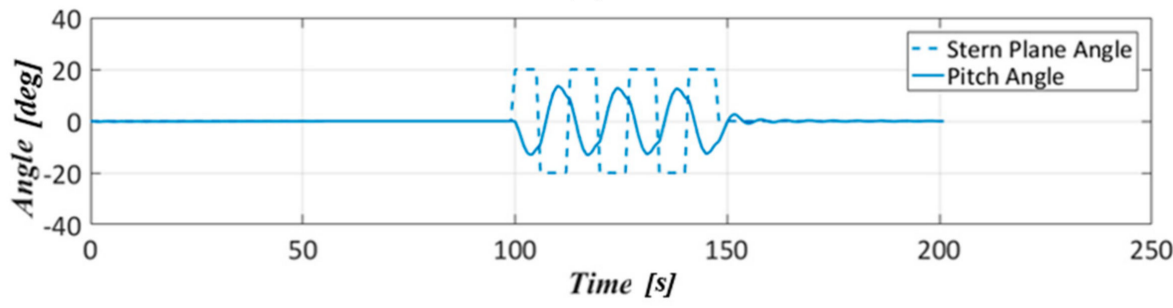

(b)

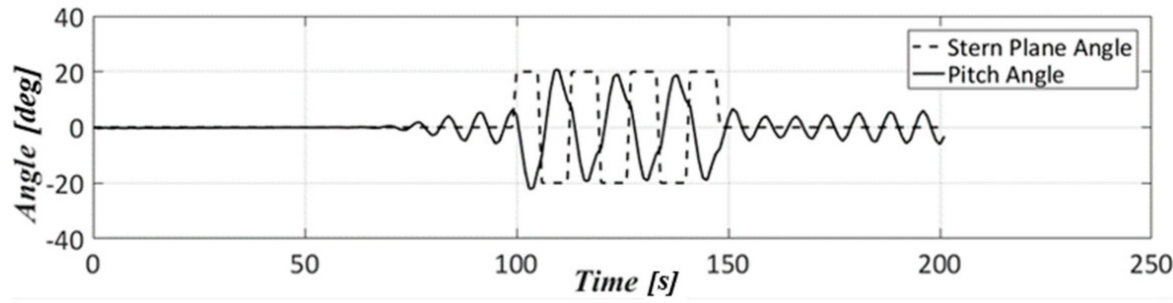

(c)

Figure 19. Comparisons of stern plane and pitch angles at sailing speeds of (a) $U=0.5,(\mathbf{b}) U=1$, and (c) $U=1.5 \mathrm{~m} / \mathrm{s}$, respectively.

Figure 20a-f illustrate the variations of time series for surge $(u)$, sway $(v)$, heave $(w)$, roll $(p)$, pitch $(q)$, and yaw rates $(r)$ at different sailing speeds. In the vertical zigzag test, both the heave rate in Figure 20c and the pitch rate in Figure 20e had the most pronounced changes, and a slight undulation was observed at high speeds. In Figure $20 \mathrm{~b}, \mathrm{f}$, the vertical zigzag has less influence on the sway and the yaw rates of the horizontal plane motion. Figure $20 \mathrm{~d}$ indicates that when $U=1.5 \mathrm{~m} / \mathrm{s}$ between 100 and $150 \mathrm{~s}$, there is a slight swing in the roll rate caused by the variation of the stern plane.

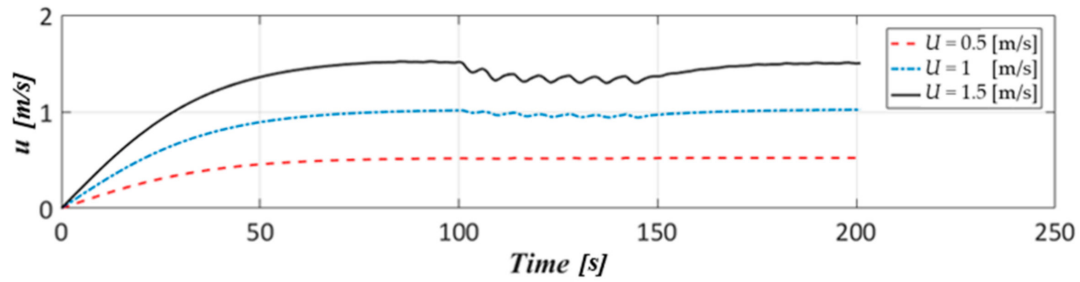

(a)

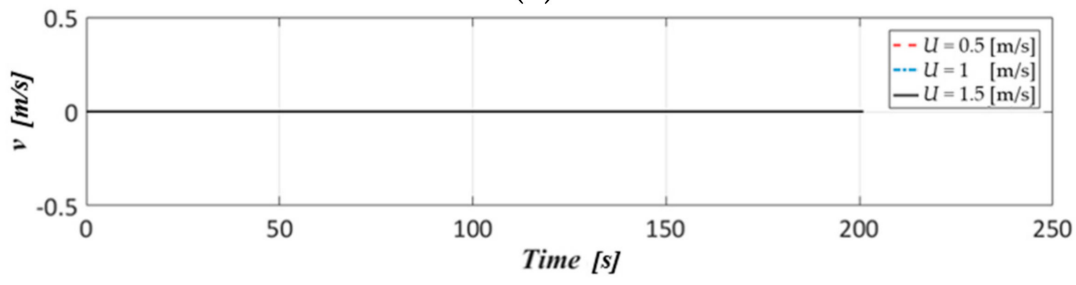

(b)

Figure 20. Conts. 


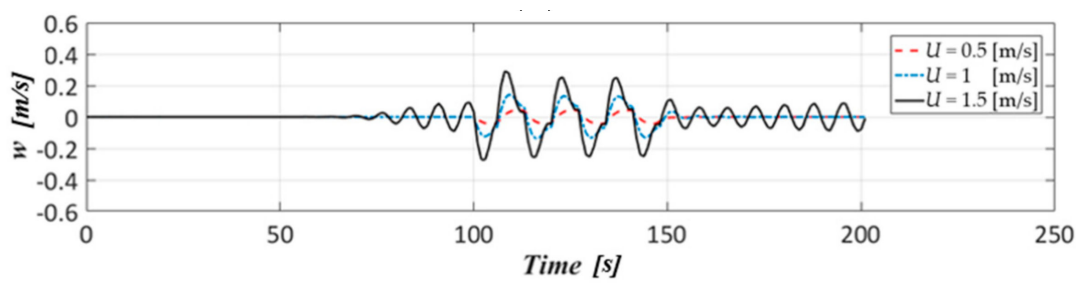

(c)

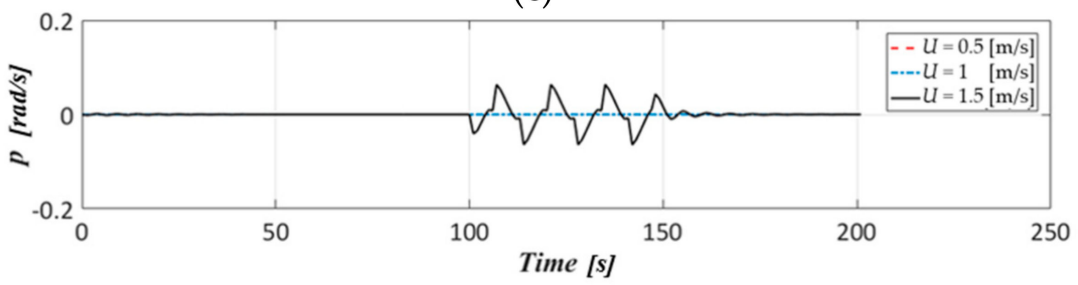

(d)

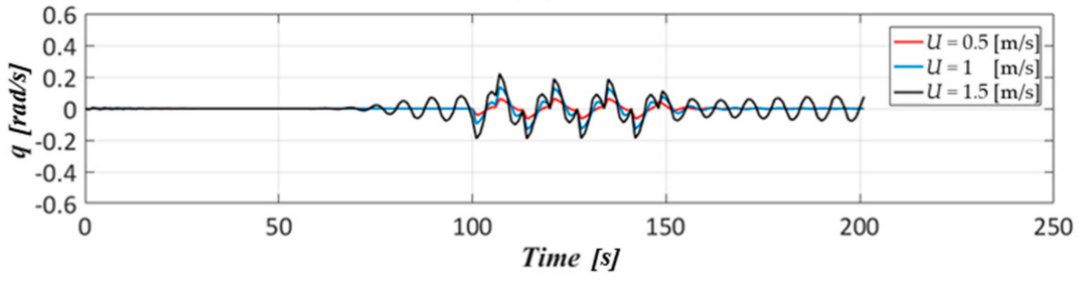

(e)

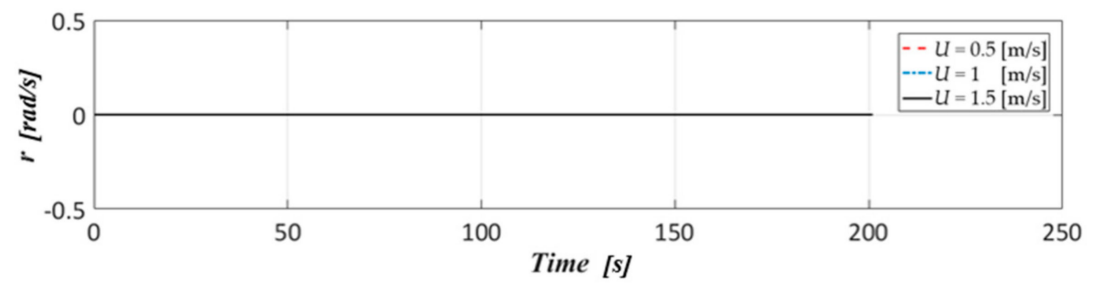

(f)

Figure 20. 6-DOF velocity components in the vertical zigzag test at different sailing speeds. (a) Surge rate: $u[\mathrm{~m} / \mathrm{s}],(\mathbf{b})$ sway rate: $v[\mathrm{~m} / \mathrm{s}],(\mathbf{c})$ heave rate: $w[\mathrm{~m} / \mathrm{s}],(\mathbf{d})$ roll rate: $p[\mathrm{rad} / \mathrm{s}],(\mathbf{e})$ pitch rate: $q[\mathrm{rad} / \mathrm{s}]$, and (f) yaw rate: $r[\mathrm{rad} / \mathrm{s}]$.

\subsubsection{Meander Test}

The meander test is similar to the vertical zigzag test, but the only difference is that the angle of the stern plane returns to zero when the desired pitch angle is reached. The main purpose of the meander test is to measure the SFRM's trajectory, motion stability, and ability to remain at a fixed depth. In the simulation, the model sailed straight for $100 \mathrm{~s}$; then, the stern plane was pulled to $20^{\circ}$ immediately, and its position was maintained for $10 \mathrm{~s}$ before the stern plane angle was reset to zero. In the meander test, the exact turning time of the stern plane was set to be $1 \mathrm{~s}$.

Figure 21 illustrates the trajectories in the meander test when the simulated SFRM moved at three different sailing speeds: $U=0.5,1$, and $1.5 \mathrm{~m} / \mathrm{s}$. The SFRM moved farther at high sailing speeds, and a slight vertical pitching motion occurred when the stern plane was reset to zero in the fixed depth test. The depth excursions are 0.051, 0.992, and $2.365 \mathrm{~m}$, corresponding to $U=0.5,1$, and $1.5 \mathrm{~m} / \mathrm{s}$. Moreover, the results of the meander tests indicated that motion stability and depth keeping ability would be unstable for the higher sailing speed by observing the variation of their trajectories. 


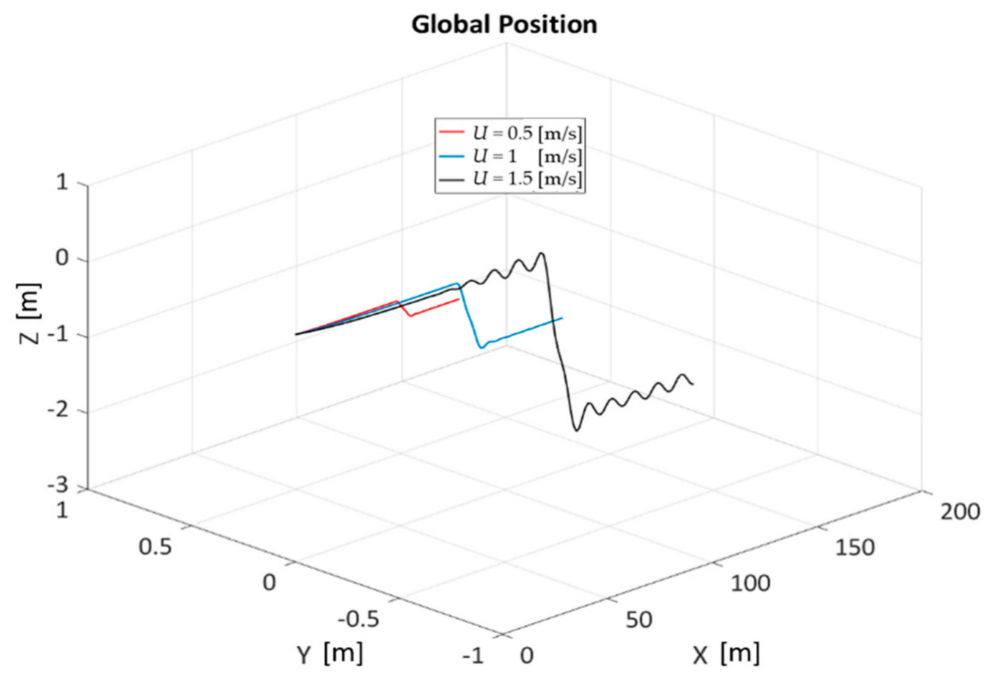

Figure 21. The SFRM's trajectories in the meander test at different sailing speeds.

Figure 22a-c illustrates the time series of the stern plane and pitch angles at different sailing speeds. The simulation results were similar to those of the vertical zigzag test and indicated a high correlation with sailing speed. Figure $22 \mathrm{a}, \mathrm{b}$ indicates that when $U=0.5$ and $1 \mathrm{~m} / \mathrm{s}$, the desired pitch angle could not be reached because of insufficient thrust force. Figure 22c indicates that when $U=1.5 \mathrm{~m} / \mathrm{s}$, the desired pitch angle was reached. These results were similar to those of the vertical zigzag test, suggesting that changes in pitch angle and ability to remain at a fixed depth have a crucial relationship with sailing speed adjustment. When conducting this test, changes in the vehicle's weight, CG, buoyancy center, and amount of inertia must be considered, and a state of neutral buoyancy must be ensured. Finally, at high speeds, relatively large undulation is likely to be observed in the pitch mode.

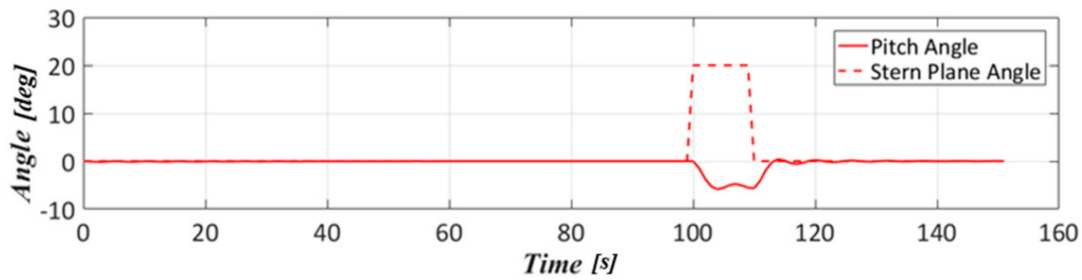

(a)

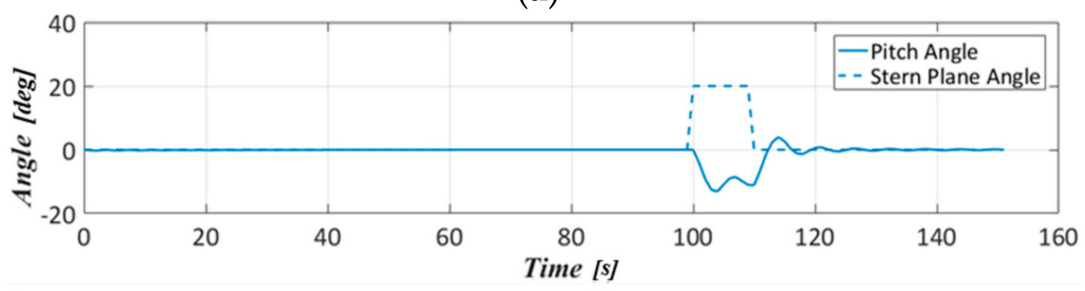

(b)

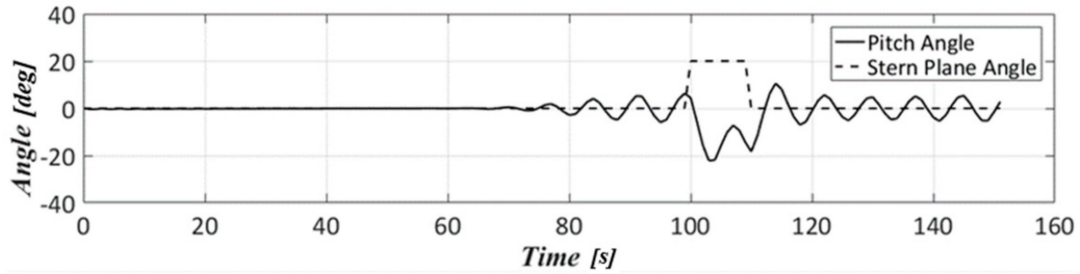

(c)

Figure 22. Comparisons of rudder and pitch angles at different sailing speeds. (a) $U=0.5$, (b) $U=1$, and (c) $U=1.5 \mathrm{~m} / \mathrm{s}$. 
Figure 23a-f displays the time series of surge $(u)$, sway $(v)$, heave $(w)$, roll $(p)$, pitch $(q)$, and yaw rates $(r)$ under different sailing speed conditions. Since the meander test is highly similar to the vertical zigzag test, changes of the heave rate in Figure 23c and the pitch rate in Figure 23e were evident. It is obvious in Figure 23b,d,f that the sway, roll, and yaw rates have little variations because the meander test is principally a test of vertical depth-determination ability.

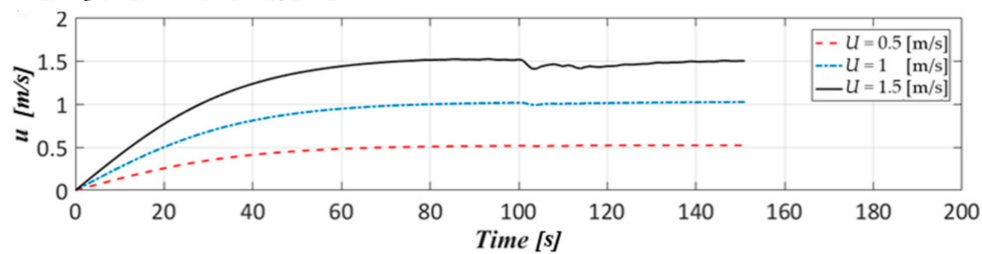

(a)

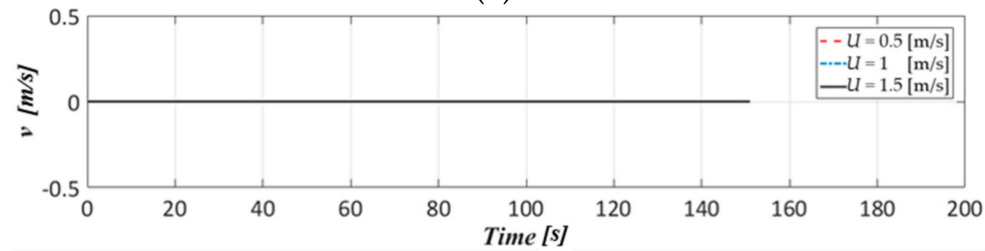

(b)

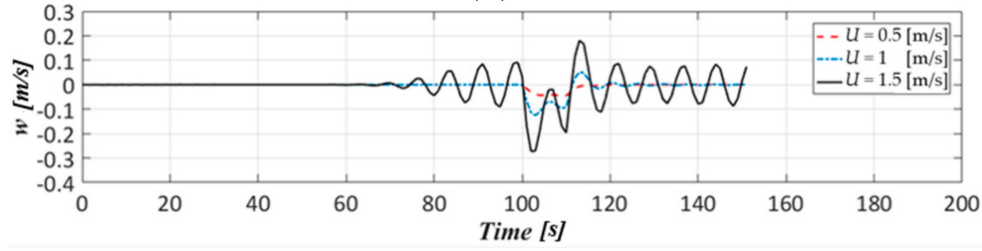

(c)

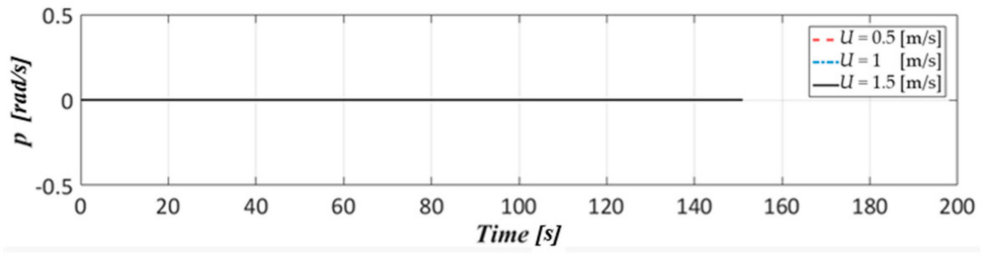

(d)

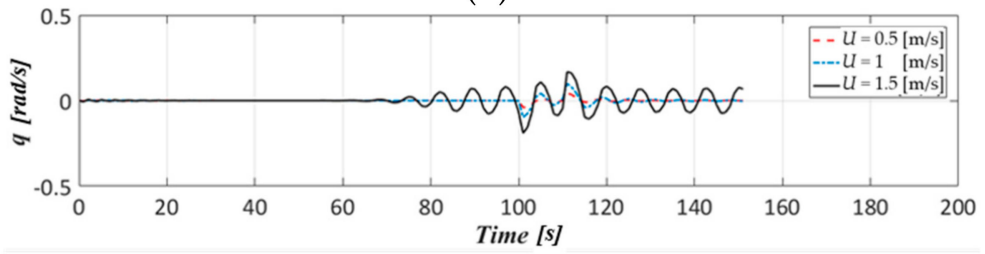

(e)

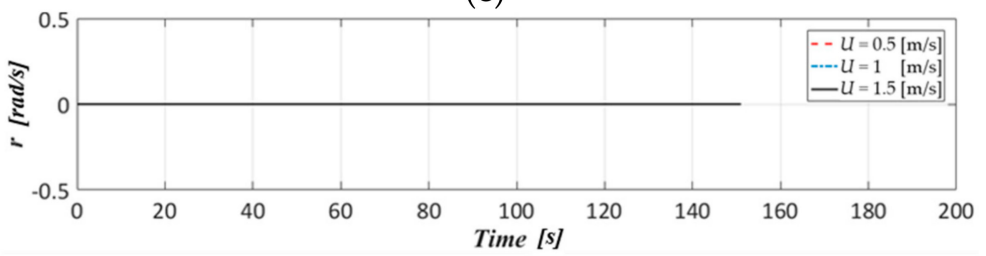

(f)

Figure 23. Time series of 6-DOF velocity components in the meander test. (a) Surge rate: $u[\mathrm{~m} / \mathrm{s}]$, (b) sway rate: $v[\mathrm{~m} / \mathrm{s}],(\mathbf{c})$ heave rate: $w[\mathrm{~m} / \mathrm{s}],(\mathbf{d})$ roll rate: $p[\mathrm{rad} / \mathrm{s}],(\mathbf{e})$ pitch rate: $q[\mathrm{rad} / \mathrm{s}]$, and (f) yaw rate: $r[\mathrm{rad} / \mathrm{s}]$. 


\subsection{Optimal PD Control Gains}

After each manoeuvring test was conducted to determine the operation limit for rudder performance, the optimal PD control gains for each test would be calculated by using the PID tuner. Figure 24a-e show the step responses, i.e., the output of the control system for a step input, of different manoeuvring tests with three sailing speeds. Since the characteristics parameters, including rise time, settling time, and overshoot, change with the variation of the control gains $\left(K_{P}, K_{D}\right)$, a set of optimal control gains can be obtained by examining the values of the characteristics parameters. To determine the efficacy of the proposed 6-DOF manoeuvring mathematical model combined with the PD controller, the PD control gains and the characteristics parameters of manoeuvring tests with the PID tuner are introduced in Table 6.

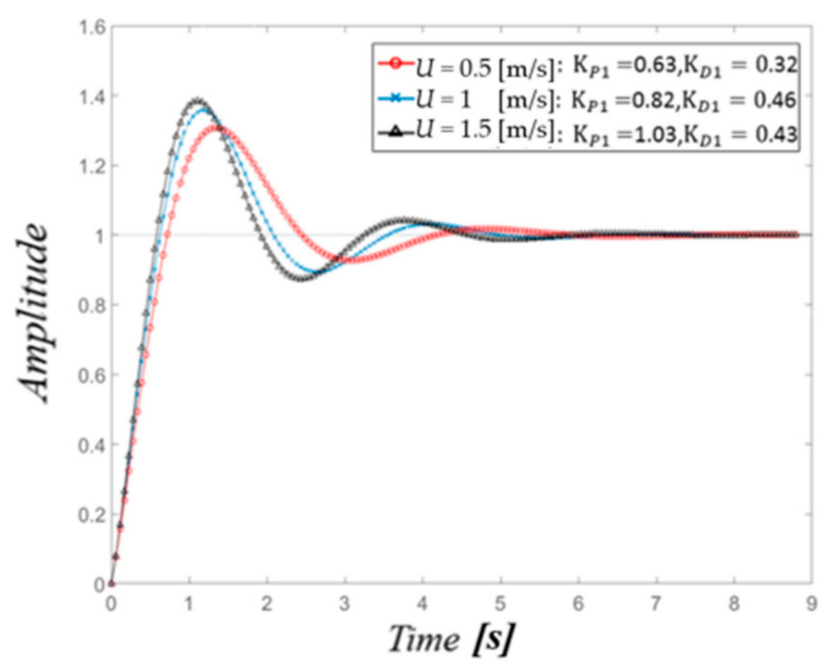

(a)

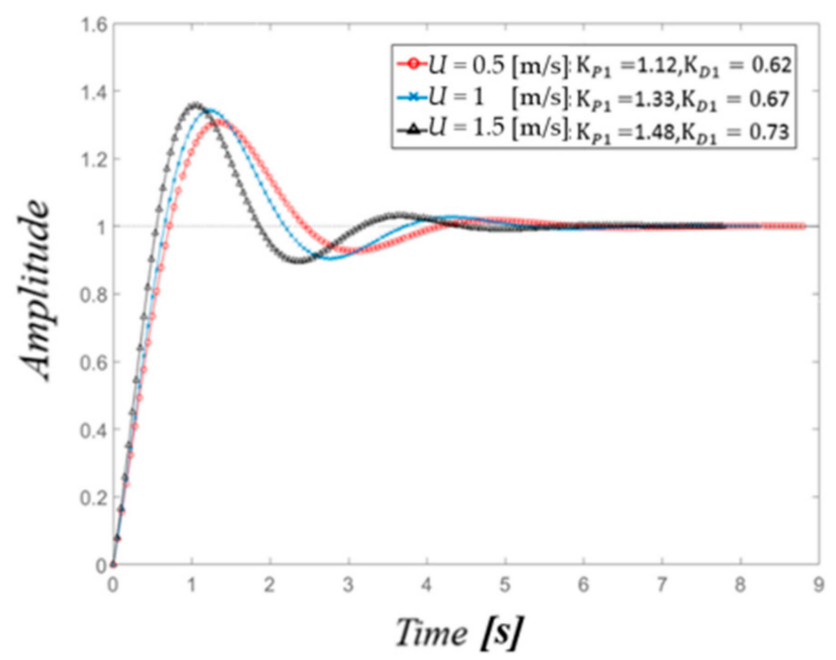

(c)

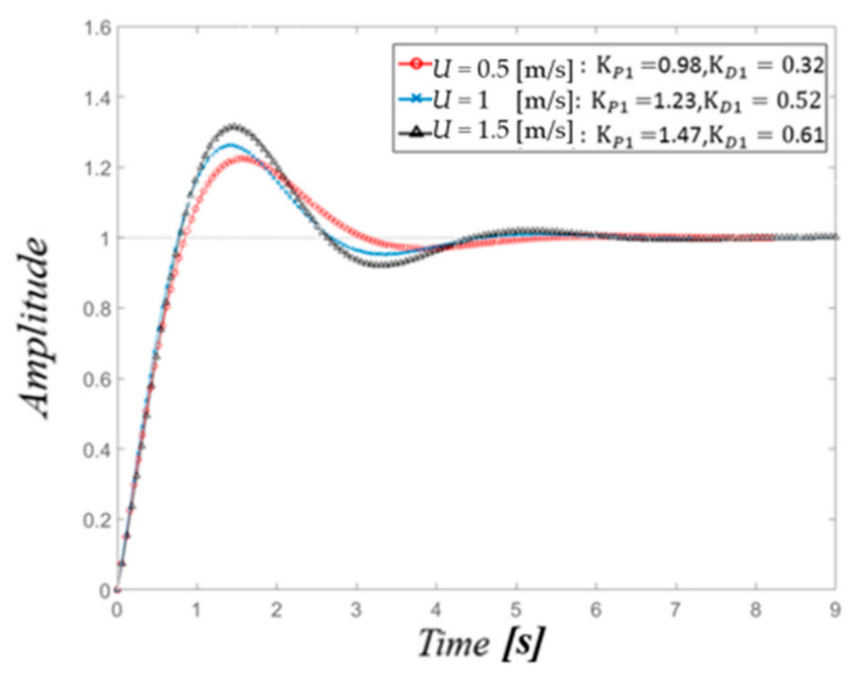

(b)

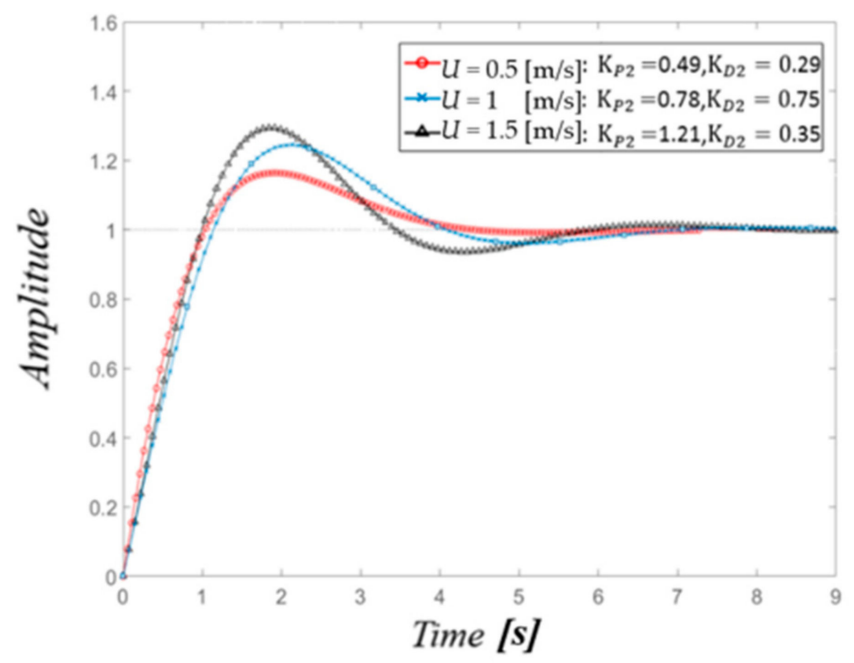

(d)

Figure 24. Conts. 


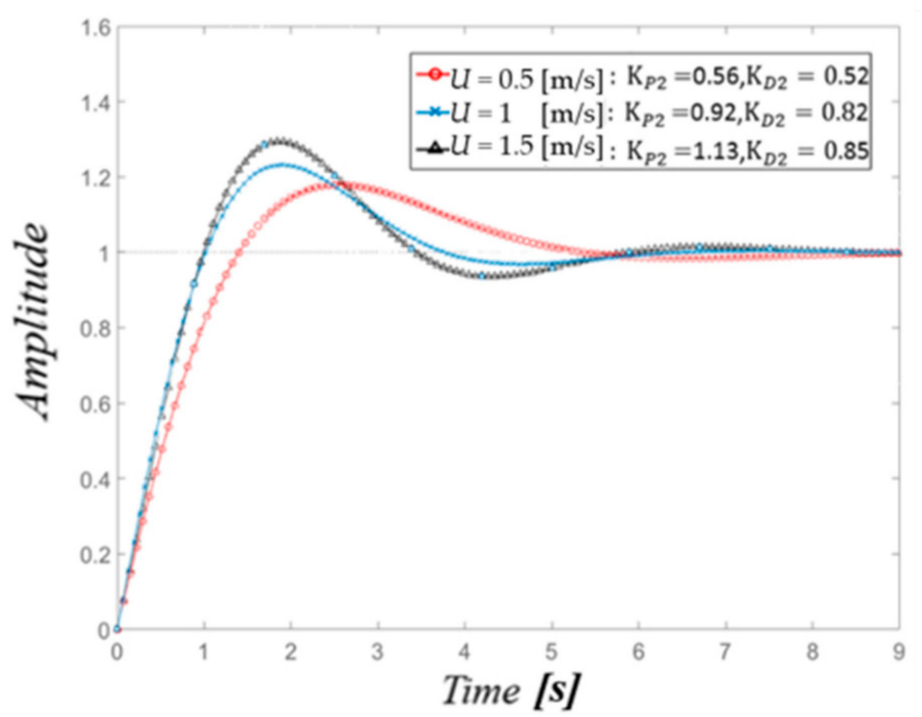

(e)

Figure 24. Step responses of the PD controller with respect to three sailing speeds, $U=0.5,1$, and $1.5 \mathrm{~m} / \mathrm{s}$, for (a) the turning circle test, (b) the horizontal zigzag test, (c) the spiral test, (d) the vertical zigzag test, and (e) the meander test.

Table 6. The characteristics parameters and the gains of the PD controller with the PID tuner for different manoeuvring tests.

\begin{tabular}{|c|c|c|c|c|c|c|c|}
\hline Test & $U[\mathrm{~m} / \mathrm{s}]$ & $K_{P}$ & $K_{D}$ & Rise Time [s] & Settling Time [s] & Overshoot [\%] & Peak \\
\hline \multirow{3}{*}{ Turning Circle } & 0.5 & 0.63 & 0.32 & 1.11 & 7.19 & 29.1 & 1.29 \\
\hline & 1 & 0.82 & 0.46 & 0.918 & 8.06 & 34.4 & 1.32 \\
\hline & 1.5 & 1.03 & 0.43 & 0.74 & 6.79 & 37.8 & 1.38 \\
\hline \multirow{3}{*}{ Horizontal ZigZag } & 0.5 & 0.98 & 0.32 & 1.09 & 6.66 & 17.8 & 1.19 \\
\hline & 1 & 1.23 & 0.52 & 0.817 & 6.48 & 24.9 & 1.25 \\
\hline & 1.5 & 1.47 & 0.61 & 0.764 & 6.42 & 31 & 1.31 \\
\hline \multirow{3}{*}{ Spiral } & 0.5 & 1.12 & 0.62 & 1.08 & 6.19 & 28.1 & 1.28 \\
\hline & 1 & 1.33 & 0.67 & 0.93 & 6.83 & 32.4 & 1.31 \\
\hline & 1.5 & 1.48 & 0.73 & 0.84 & 6.79 & 36.8 & 1.33 \\
\hline \multirow{3}{*}{ Vertical ZigZag } & 0.5 & 0.49 & 0.29 & 0.856 & 5.42 & 12.8 & 1.15 \\
\hline & 1 & 0.78 & 0.75 & 0.981 & 6.71 & 22.8 & 1.25 \\
\hline & 1.5 & 1.21 & 0.35 & 0.869 & 6.04 & 29.7 & 1.3 \\
\hline \multirow{3}{*}{ Meander } & 0.5 & 0.56 & 0.52 & 1.28 & 6.69 & 17.5 & 1.18 \\
\hline & 1 & 0.92 & 0.82 & 0.866 & 6.03 & 19.5 & 1.22 \\
\hline & 1.5 & 1.13 & 0.85 & 0.809 & 6.68 & 28.4 & 1.28 \\
\hline
\end{tabular}

For the manoeuvring tests in the horizontal plane, i.e., turning circle, horizontal zigzag and spiral tests, the turning circle test has the largest percentage of overshoot on the basis of different sailing speeds. By contrast, the horizontal zigzag test and the spiral test have less amounts of overshoot than the turning circle test. Furthermore, the horizontal zigzag test has the minimum amount of overshoot, rise time, and settling time among all of the horizontal plane tests. In terms of the optimum action of the PD controller, the horizontal zigzag test has a better performance than the other two horizontal-plane tests.

For the manoeuvring tests in the vertical plane, i.e., vertical zigzag and meander tests, the amounts of overshoot for the meander test appear to be less than those for the vertical zigzag test mostly. On the other hand, the vertical zigzag test has a better performance of settling time than the meander test. In general, the values of rise time for the meander test 
are smaller than those for the vertical zigzag test. Consequently, it is difficult to judge the efficacy of the PID tuner by comparing the vertical zigzag test with the meander test.

\subsection{Autopilot Simulation}

In order to test turning and diving abilities of the SFRM with the PD controller, a 3D map with numerous waypoints was established. The coordinates of waypoints in the 3D map are described in Table 7. An autopilot system consists of a 6-DOF manoeuvring mathematical model and a course-keeping PD controller for an LOS-based guidance system. Simulation results of tuning PD control on the rudder planes and the stern planes would be presented by comparing with two types of controlling modes, i.e., A-type and B-type. It is worth mentioning that the PD control gains of the A-type controller are tuned by the horizontal zigzag test and the vertical zigzag test, whereas the ones of the B-type controller are tuned by the horizontal zigzag test and the meander test, respectively.

Table 7. The coordinates of waypoints in the 3D map. Unit: [m].

\begin{tabular}{cc}
\hline Waypoint Number & Coordinate $\mathbf{X}, \mathbf{Y}, \mathbf{Z})$ \\
\hline 1 & $(20,0,0)$ \\
\hline 2 & $(20,-35,-5)$ \\
\hline 3 & $(55,-35,-10)$ \\
\hline 4 & $(55,0,-15)$ \\
\hline 5 & $(90,0,-20)$ \\
\hline 6 & $(90,-35,-25)$ \\
\hline 7 & $(125,-35,-30)$ \\
\hline 8 & $(125,0,-35)$ \\
\hline 9 & $(145,0,-40)$ \\
\hline
\end{tabular}

Figure 25a-c shows the trajectories of the SFRM with three-view angles based on $U=1.5 \mathrm{~m} / \mathrm{s}$ in the 3D map by comparing the A-type with the B-type controllers. Comprehensively, the total sailing distance of the A-type controller is $382 \mathrm{~m}$ with the sailing time of $297 \mathrm{~s}$, whereas the total sailing distance of the B-type controller is $387 \mathrm{~m}$ with the sailing time of $301 \mathrm{~s}$. Compared with the B-type controller, the A-type controller is capable of saving $1.3 \%$ sailing distance and $0.7 \%$ sailing time. Although both simulated trajectories are very similar to each other, the A-type controller appears to have better performances of turning and diving abilities than those of the B-type.

Figure 26a,b presents variations of the rudder angle and the stern plane angle in the time domain. It is clearly found that both the rudder angle and the stern plane angle of the A-type controller are more sensitive to changes in the course angles during the passage.

On the other hand, time records of 6-DOF velocity components of the SFRM with the A-type and B-type controllers are illustrated in Figure 27a-f, respectively. There are large differences of heave rates (Figure 27c) and pitch rates (Figure 27e) between the A-type and the B-type controllers. Generally speaking, the A-type controller appears to have faster motion responses, especially for the heave rate and the pitch rate, than the B-type. The average power spent by the A-type controller is $5.02 \mathrm{~W}$, which is better than $5.01 \mathrm{~W}$ spent by the B-type controller. In addition, the entire work done by using the A-type controller is $1490.94 \mathrm{~J}$, whereas the result by using the B-type controller is $1508.01 \mathrm{~J}$. In the case of efficiency, it would be more appropriate to adopt the A-type controller than the B-type in the autopilot simulation of the SFRM. 


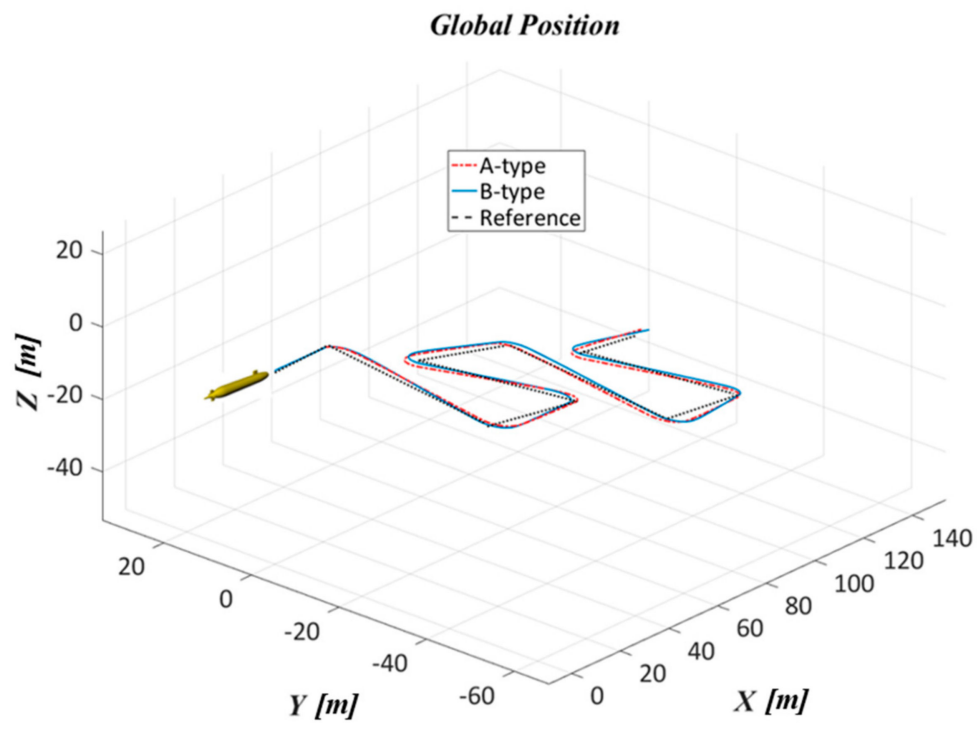

(a)

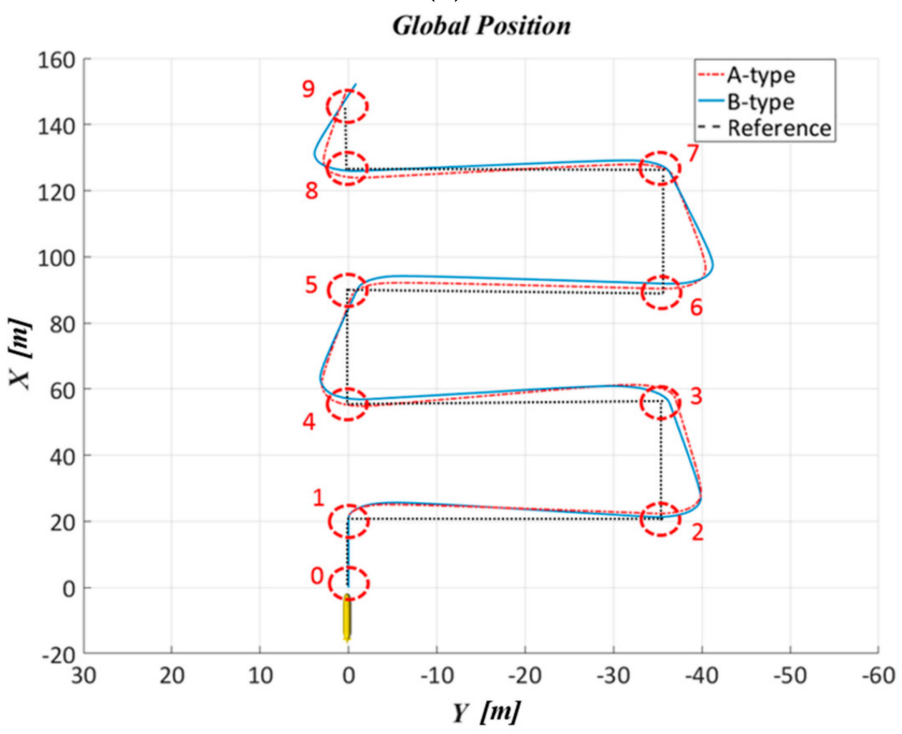

(b)

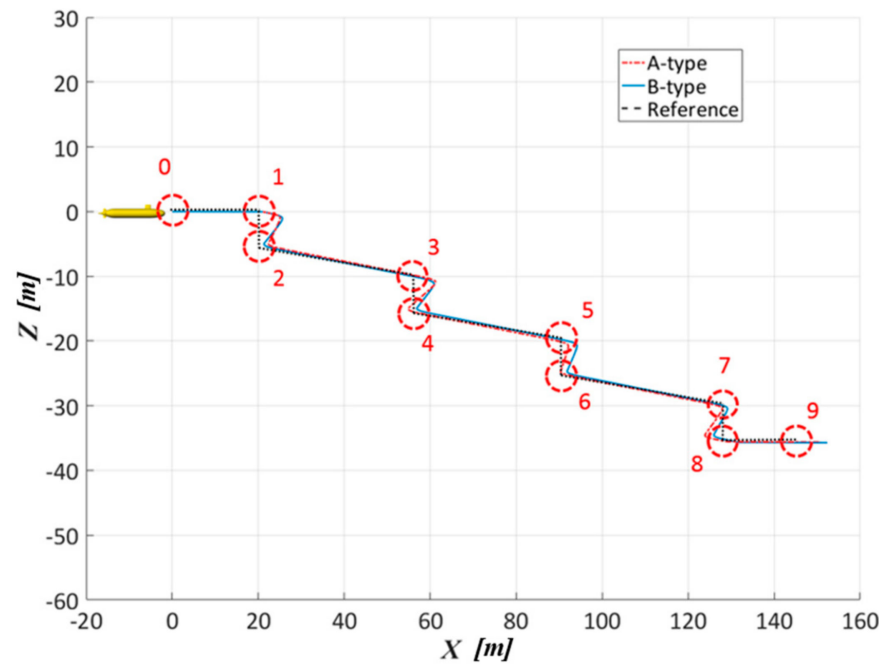

(c)

Figure 25. Sailing trajectories of the SFRM by comparing the A-type controller with the B-type controller in (a) the stereo view; (b) the top view; and (c) the side view, respectively. 


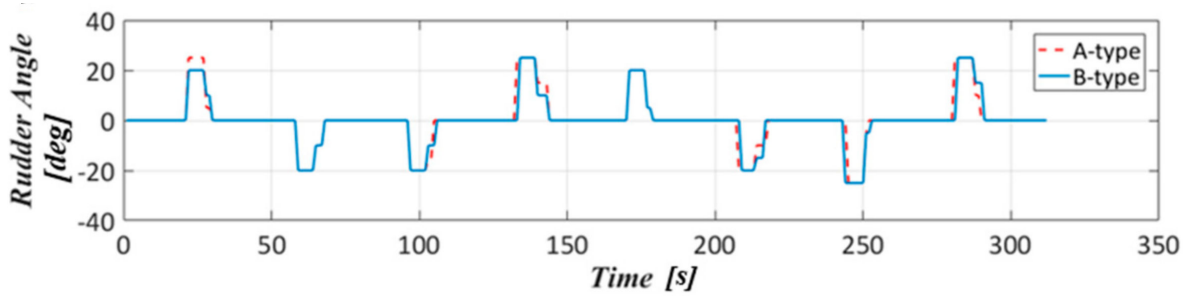

(a)

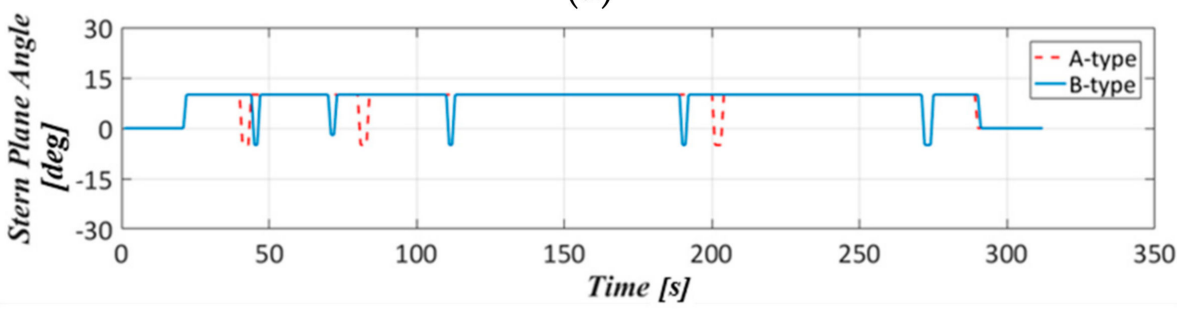

(b)

Figure 26. Time series of (a) rudder angle, and (b) stern plane angles for the A-type and B-type controllers, respectively.

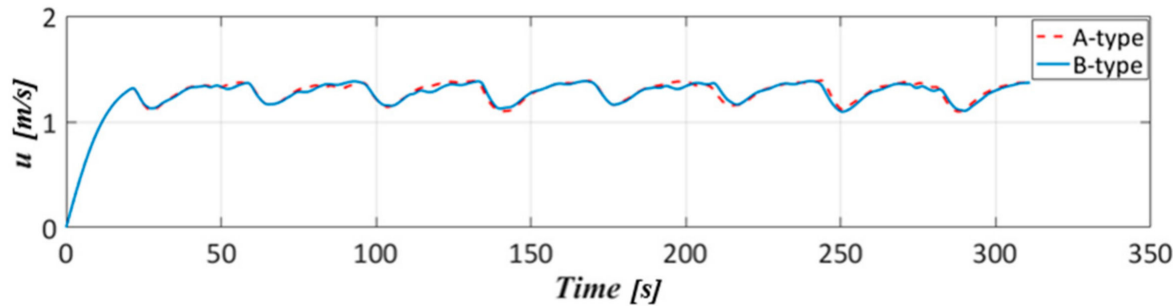

(a)

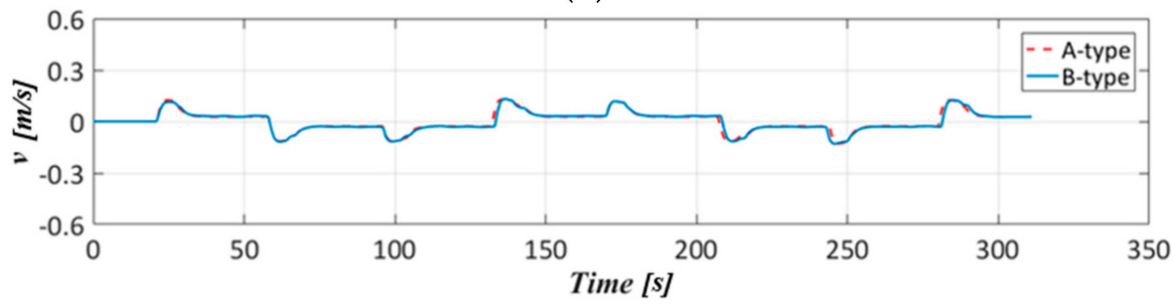

(b)

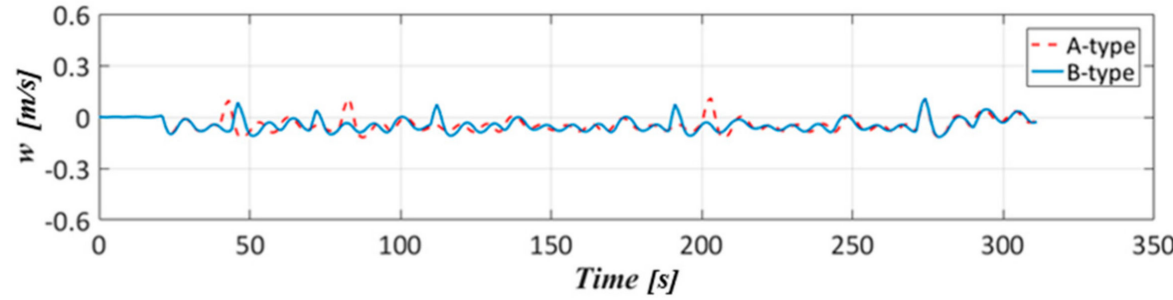

(c)

Figure 27. Conts. 


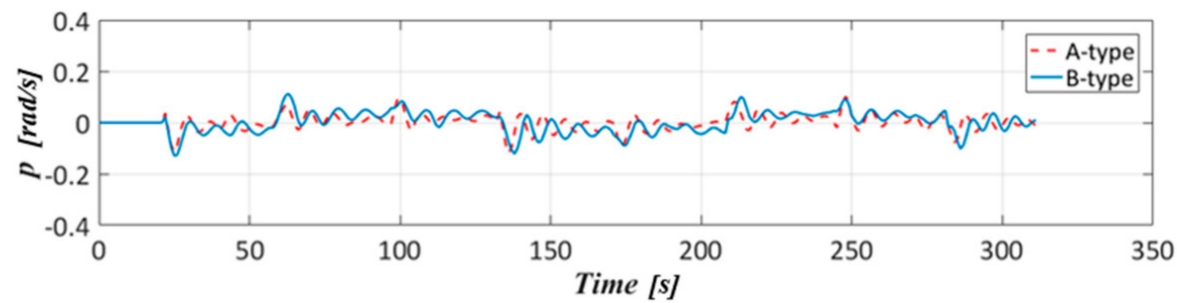

(d)

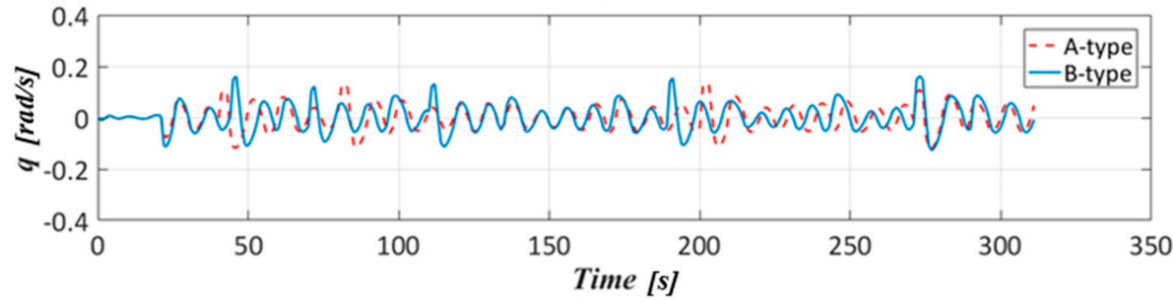

(e)

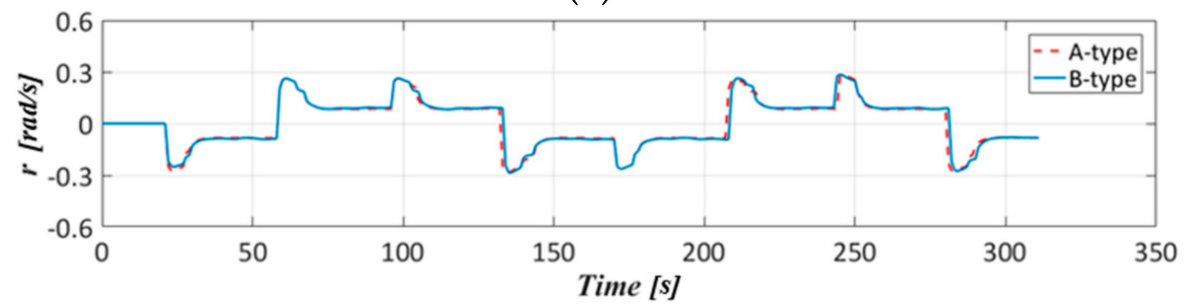

(f)

Figure 27. Time series of velocity components. (a) Surge rate: $u[\mathrm{~m} / \mathrm{s}],(\mathbf{b})$ sway rate: $v[\mathrm{~m} / \mathrm{s}]$, (c) heave rate: $w[\mathrm{~m} / \mathrm{s}],(\mathbf{d})$ roll rate: $p[\mathrm{rad} / \mathrm{s}],(\mathbf{e})$ pitch rate: $q[\mathrm{rad} / \mathrm{s}]$, and (f) yaw rate: $r[\mathrm{rad} / \mathrm{s}]$ for the A-type and B-type controllers, respectively.

\section{Conclusions}

In this study, the 6-DOF manoeuvring mathematical model of the SFRM with the autopilot system was developed to conduct a preliminary evaluation of motion performance for optimal control gains. In order to realise the turning and diving performances of the SFRM, a series of manoeuvring tests, including turning circle, horizontal zigzag, vertical zigzag, meander, and spiral tests, would be implemented based on three sailing speeds with empty ballast tanks. Furthermore, the PID tuner was used to acquire the optimal control gains for each manoeuvring test by considering characteristics parameters. Therefore, two types of control gains by combining different horizontal plane motion tests with vertical plane motion tests were adopted for subsequent autopilot simulation. The post-processor based on the Cinema 4D modelling is capable of allowing the animated model to match the simulated trajectories and course angles graphically. The concluding remarks can be summarised as below:

1. There were only linear terms of hydrodynamic coefficients considered in the present simulation regardless of the scale effect. The sailing speed and the operation of control surface were considered as the influential parameters in the manoeuvring tests with empty ballast tanks.

2. Through a series of manoeuvring tests, the operation performances by adopting different combinations of rudder commands and sailing speeds were well analysed.

3. After evaluating the characteristics parameters of the PD controller for manoeuvring tests in the horizontal and vertical plane, both the A-type (horizontal zigzag plus vertical zigzag) and the B-type (horizontal zigzag plus meander) controllers were compared in the autopilot simulation. 
4. When conducting the autopilot simulation in the 3D map, the A-type PD controller with the LOS guidance algorithm was proved to be more efficient than the B-type in the average power, total sailing distance, and consuming time.

5. In case of low-speed conditions, the SFRM can not reach the desired pitch angle with empty ballast tanks. In the future study, the PD control on the ballast tanks and the attitude adjusting system will be considered in the autopilot system of the SFRM for improving its stability and manoeuvrability.

Author Contributions: Y.-H.L. is the principal investigator and Y.-T.L. and Y.-J.C. are the research assistants in this project. All authors have read and agreed to the published version of the manuscript.

Funding: This research was funded by the Ministry of Science and Technology for a grant under Contract No. MOST 109-2221-E-006-100-MY2.

Data Availability Statement: Data sharing not applicable.

Conflicts of Interest: The authors declare no conflict of interest.

\section{References}

1. Bettle, M. Unsteady Computational Fluid Dynamics Simulations of Six Degrees-of-Freedom Submarine Manoeuvres. Ph.D. Thesis, University of New Brunswick, Fredericton, NB, Canada, 2013.

2. Itard, X. Recovery procedure in case of flooding. In Proceedings of Warship '99: Naval Submarines; RINA: London, UK, 1999.

3. Issac, M.T.; Adams, S.; He, M.; Bose, N.; Williams, C.D.; Bachmayer, R.; Crees, T. Manoeuvring Experiments Using the MUN Explorer AUV. In Proceedings of the 2007 Symposium on Underwater Technology and Workshop on Scientific Use of Submarine Cables and Related Technologies, Tokyo, Japan, 17-20 April 2007; pp. 256-262.

4. Jun, B.H.; Park, J.-Y.; Lee, F.-Y.; Lee, P.-M.; Lee, C.-M.; Kim, K.; Lim, Y.K.; Oh, J.H. Development of the AUV 'ISiMI'and a free running test in an Ocean Engineering Basin. Ocean Eng. 2009, 36, 2-14. [CrossRef]

5. Overpelt, B.; Nienhuis, B.; Anderson, B. Free Running Manoeuvring Model Tests on a Modern Generic SSK Class Submarine (BB2). In Proceedings of the Pacific International Maritime Conference, Sydney, Australia, 18-20 August 2015; pp. 1-14.

6. Gertler, M.; Hagen, G.R. Standard Equations of Motion for Submarine Simulation; David w Taylor Naval Ship Research and Development Center: Bethesda, MD, USA, 1967.

7. Feldman, J. Dtnsrdc Revised Standarrd Submarine Equations of Motion; David w Taylor Naval Ship Research and Development Center: Bethesda, MD, USA, 1979.

8. Yoon, H.K.; Rhee, K.P. Identification of hydrodynamic coefficients in ship maneuvering equations of motion by estimation-beforemodeling technique. Ocean Eng. 2003, 30, 2379-2404. [CrossRef]

9. Lin, Y.-H.; Li, X.-C. The Investigation of a Sliding Mesh Model for Hydrodynamic Analysis of a SUBOFF Model in Turbulent Flow Fields. J. Mar. Sci. Eng. 2020, 8, 744. [CrossRef]

10. Kim, H.; Ranmuthugala, D.; Leong, Z.Q.; Chin, C. Six-DOF simulations of an underwater vehicle undergoing straight line and steady turning manoeuvres. Ocean Eng. 2018, 150, 102-112. [CrossRef]

11. Lin, Y.-H.; Tseng, S.-H.; Chen, Y.-H. The experimental study on maneuvering derivatives of a submerged body SUBOFF by implementing the Planar Motion Mechanism tests. Ocean Eng. 2018, 170, 120-135. [CrossRef]

12. Yildiz, Ö; Gökalp, R.B.; Yilmaz, A.E. A review on motion control of the underwater vehicles. In Proceedings of the 2009 International Conference on Electrical and Electronics Engineering-ELECO 2009, Bursa, Turkey, 5-8 November 2009; pp. II-337-II-341.

13. Herman, P. Decoupled PD set-point controller for underwater vehicles. Ocean Eng. 2009, 36, 529-534. [CrossRef]

14. Soylu, S.; Buckham, B.J.; Podhorodeski, R.P. A chattering-free sliding-mode controller for underwater vehicles with fault-tolerant infinity-norm thrust allocation. Ocean Eng. 2008, 35, 1647-1659. [CrossRef]

15. Qi, X. Adaptive coordinated tracking control of multiple autonomous underwater vehicles. Ocean Eng. 2014, 91, 84-90. [CrossRef]

16. Mohan, S.; Kim, J. Indirect adaptive control of an autonomous underwater vehicle-manipulator system for underwater manipulation tasks. Ocean Eng. 2012, 54, 233-243. [CrossRef]

17. Jun, S.W.; Lee, H.J. Design of TS fuzzy-model-based controller for depth control of autonomous underwater vehicles with parametric uncertainties. In Proceedings of the 2011 11th International Conference on Control, Automation and Systems; ICROS, Gyeonggi-do, Korea, 26-29 October 2011; pp. 1682-1684.

18. Steenson, L.V.; Phillips, A.B.; Turnock, S.R.; Furlong, M.E.; Rogers, E. Effect of measurement noise on the performance of a depth and pitch controller using the model predictive control method. In Proceedings of the 2012 IEEE/OES Autonomous Underwater Vehicles (AUV), Southampton, UK, 24-27 September 2012; pp. 1-8.

19. Subudhi, B.; Mukherjee, K.; Ghosh, S. A static output feedback control design for path following of autonomous underwater vehicle in vertical plane. Ocean Eng. 2013, 63, 72-76. [CrossRef]

20. Xu, B.; Pandian, S.R.; Sakagami, N.; Petry, F. Neuro-fuzzy control of underwater vehicle-manipulator systems. J. Frankl. Inst. 2012, 349, 1125-1138. [CrossRef] 
21. Cooney, L.A. Dynamic Response and Maneuvering Strategies of a Hybrid Autonomous Underwater Vehicle in Hovering; Massachusetts Institute of Technology: Cambridge, MA, USA, 2009.

22. Fossen, T.I.; Fjellstad, O.-E. Nonlinear modelling of marine vehicles in 6 degrees of freedom. Math. Model. Syst. 1995, 1, 17-27. [CrossRef]

23. Perrault, D.; Bose, N.; O'Young, S.; Williams, C.D. Sensitivity of AUV response to variations in hydrodynamic parameters. Ocean Eng. 2003, 30, 779-811. [CrossRef]

24. Coe, R.G. Improved Underwater Vehicle Control and Maneuvering Analysis with Computational Fluid Dynamics Simulations; Virginia Tech: Blacksburg, VA, USA, 2013.

25. Boger, D.; Davoudzadeh, F.; Dreyer, J.; McDonald, H.; Schott, C.; Aierke, W.; Arabshahi, A.; Briley, W.R.; Busby, J.A.; Chen, J.P.; et al. A Physics-Based Means of Computing the Flow around a Maneuvering underwater Vehicle; Applied Research Laboratory: State College, PA, USA, 1997.

26. Healey, A.J.; Lienard, D. Multivariable sliding mode control for autonomous diving and steering of unmanned underwater vehicles. IEEE J. Ocean. Eng. 1993, 18, 327-339. [CrossRef]

27. Roddy, R.F. Investigation of the Stability and Control Characteristics of Several Configurations of the DARPA SUBOFF Model (DTRC Model 5470) from Captive-Model Experiments; David Taylor Research Center Bethesda MD Ship Hydromechanics Dept: Bethesda, MD, USA, 1990.

28. Antonelli, G. On the use of adaptive/integral actions for six-degrees-of-freedom control of autonomous underwater vehicles. IEEE J. Ocean. Eng. 2007, 32, 300-312. [CrossRef]

29. McGookin, E.W.; Murray-Smith, D.J.; Li, Y.; Fossen, T.I. The optimization of a tanker autopilot control system using genetic algorithms. Trans. Inst. Meas. Control 2000, 22, 141-178. [CrossRef]

30. Xinghua, C.; Juan, L. AUV Planner Tracking Control based on the Line of Sight Guidance Method. In Proceedings of the 2014 IEEE International Conference on Mechatronics and Automation, Tianjin, China, 3-6 August 2014; pp. $1204-1208$.

31. McGookin, E.W.; Murray-Smith, D.J.; Li, Y.; Fossen, T.I. Ship steering control system optimisation using genetic algorithms. Control Eng. Pract. 2000, 8, 429-443. [CrossRef]

32. Wang, X.; Wu, G. Modified LOS Path Following Strategy of a Portable Modular AUV Based on Lateral Movement. J. Mar. Sci. Eng. 2020, 8, 683. [CrossRef]

33. Yadav, M.; Tayal, V.K. Performance Enhancement of Induction Motor Using PID Controller with PID Tuner. In Advances in Interdisciplinary Engineering; Springer: Berlin/Heidelberg, Germany, 2019; pp. 783-793.

34. McQuilkin, K.; Powers, A. Cinema 4D: the Artist's Project Sourcebook; Taylor \& Francis: New York, NY, USA, 2011.

35. Renilson, M. Submarine Hydrodynamics; Springer: Berlin/Heidelberg, Germany, 2015.

36. Molland, A.F. The Maritime Engineering Reference Book: A Guide to Ship Design, Construction and Operation; Elsevier: Amsterdam, The Netherlands, 2011. 